RESEARCH

SERIES

NUMBER 111

December

2020

\section{REGIONAL DEMOGRAPHICS AND STRUCTURAL HOUSING DEMAND AT A COUNTY LEVEL}

\section{ADELE BERGIN AND ABIÁN GARCÍA-RODRÍGUEZ}

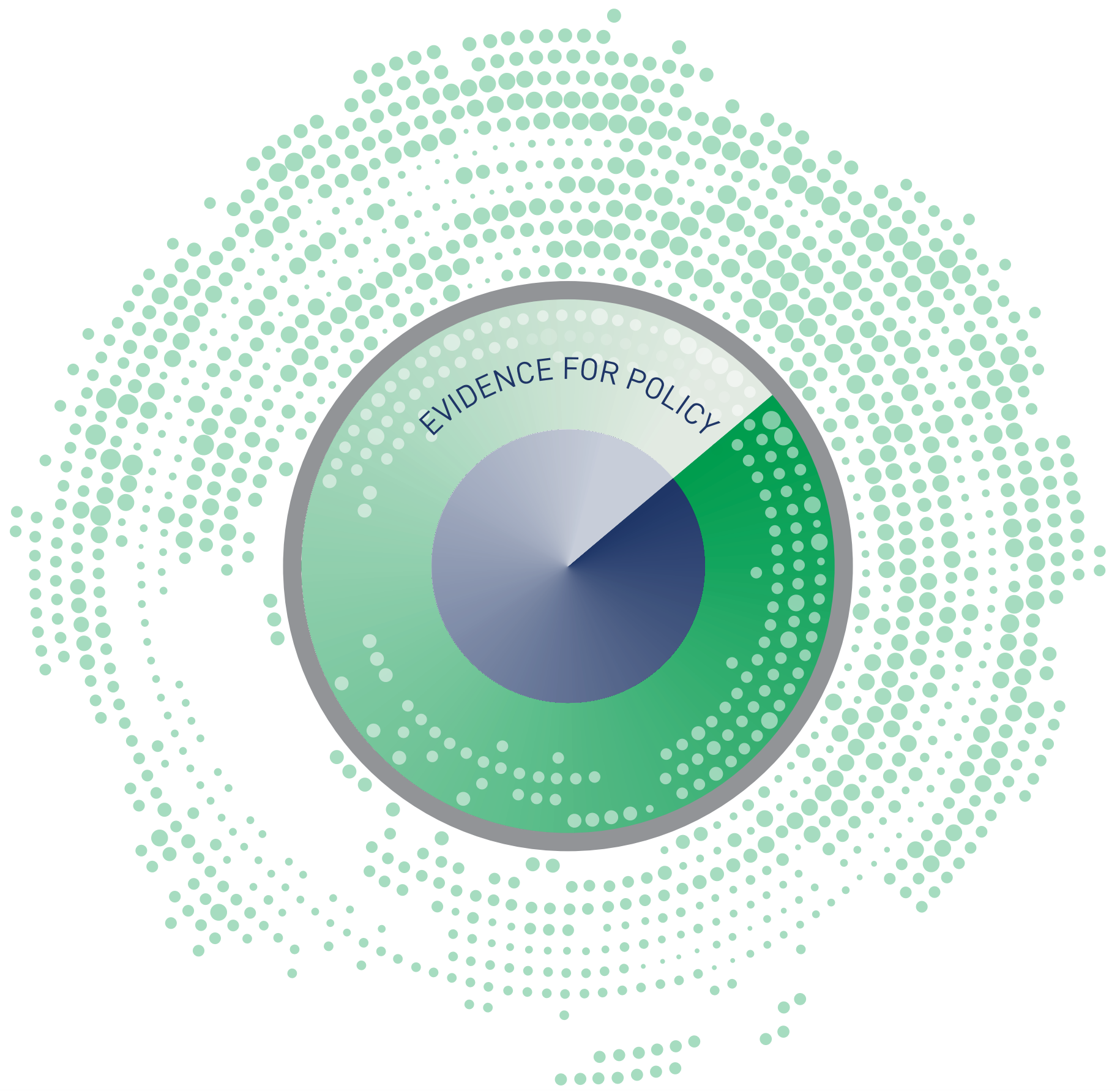




\section{REGIONAL DEMOGRAPHICS AND STRUCTURAL HOUSING DEMAND AT A COUNTY LEVEL}

Adele Bergin

Abián García-Rodríguez

December 2020

\section{RESEARCH SERIES}

\section{NUMBER 111}

Economic and Social Research Institute;

Department of Housing, Local Government and Heritage

Available to download from www.esri.ie

(C) The Economic and Social Research Institute

Whitaker Square, Sir John Rogerson's Quay, Dublin 2

DOI: https://doi.org/10.26504/rs111

ISBN: 978-0-7070-0539-3

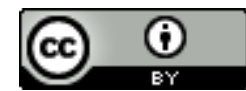

This Open Access work is licensed under a Creative Commons Attribution 4.0 International License (https://creativecommons.org/licenses/by/4.0/), which permits unrestricted use, distribution, and reproduction in any medium, provided the original work is properly credited. 



\section{ABOUT THE ESRI}

The mission of the Economic and Social Research Institute is to advance evidencebased policymaking that supports economic sustainability and social progress in Ireland. ESRI researchers apply the highest standards of academic excellence to challenges facing policymakers, focusing on 12 areas of critical importance to $21^{\text {st }}$ Century Ireland.

The Institute was founded in 1960 by a group of senior civil servants led by Dr T.K. Whitaker, who identified the need for independent and in-depth research analysis to provide a robust evidence base for policymaking in Ireland.

Since then, the Institute has remained committed to independent research and its work is free of any expressed ideology or political position. The Institute publishes all research reaching the appropriate academic standard, irrespective of its findings or who funds the research.

The quality of its research output is guaranteed by a rigorous peer review process. ESRI researchers are experts in their fields and are committed to producing work that meets the highest academic standards and practices.

The work of the Institute is disseminated widely in books, journal articles and reports. ESRI publications are available to download, free of charge, from its website. Additionally, ESRI staff communicate research findings at regular conferences and seminars.

The ESRI is a company limited by guarantee, answerable to its members and governed by a Council, comprising 14 members who represent a cross-section of ESRI members from academia, civil services, state agencies, businesses and civil society. The Institute receives an annual grant-in-aid from the Department of Public Expenditure and Reform to support the scientific and public interest elements of the Institute's activities; the grant accounted for an average of 30 per cent of the Institute's income over the lifetime of the last Research Strategy. The remaining funding comes from research programmes supported by government departments and agencies, public bodies and competitive research programmes.

Further information is available at www.esri.ie 


\section{THE AUTHORS}

Adele Bergin is an Associate Research Professor and Abián García-Rodríguez is a Research Officer at the Economic and Social Research Institute (ESRI). All members of the research team have adjunct research positions at Trinity College Dublin.

\section{ACKNOWLEDGEMENTS}

This research has been funded by the Irish Department of Housing, Local Government and Heritage under the collaborative research programme between the Department and the ESRI. We would like to thank all the individuals within the Department who provided assistance and advice during the project, particularly Eoin Corrigan, Laura Flannelly and George Hussey. Valuable contributions were also made by members of the Research Programme Steering Committee. Finally, our thanks go to Professor Kieran McQuinn (Head of Economic Analysis in the ESRI), Professor Alan Barrett (Director of the ESRI) and two internal ESRI referees for their suggestions and contributions to this report. 


\section{FOREWORD}

The issue of forecasting the future demand for housing is a critical input to planning for a growing population. Managing the future location, typology and tenure of housing is a key function of each local authority and requires a robust evidence base and approach to implementation. More and better housing data at national, regional, local authority and settlement level is needed to improve our understanding of structural housing demand and the housing needs of people, in order to develop evidence-based and cost-effective policies, programmes and funding initiatives.

Demand for housing is largely a function of population growth and housing preferences, and population growth is largely determined by economic conditions. Economic conditions can vary significantly within the State at any point in time but employment and educational opportunities tend to be the most relevant drivers of migration within the State.

Heretofore projections of future housing demand tended to take account of some, but not all of these important inputs with varying levels of consistency in the methodologies employed to estimate population into the future. Ensuring that that projections are underpinned by the most relevant assumptions, particularly for the purposes of housing and planning, results in a strong evidence base from which responsive and effective policies can be developed, at a national, regional and local level.

The Department is keen to further strengthen an evidence-based policymaking approach to housing and the collaboration with the ESRI on research of this nature marks a significant State-funded effort to incorporate all of the relevant inputs in a manner that provides the Department, local authorities and other State organisations a range of county-level scenarios for future population and housing demand, which can be used across a number of domains. This builds on the work on population forecasting as part of Project Ireland 2040 which has influenced the National Planning Framework (NPF) and Regional Economic and Spatial Strategies.

This paper was guided by the Steering Committee which oversees the research collaboration between the Department and the Institute. The Steering Committee includes representatives from the Department, the Institute, the Housing Agency, the Residential Tenancies Board, as well as the relevant business units of the Department. This paper is a significant output of the research collaboration 
between the Institute and the Department, which also looks at broader issues where spatial planning and housing issues intercept.

One of the main reasons for funding this work is to provide required data input for the process of Housing Needs Demand Assessment (HNDA) by local authorities, which the local authorities will undertake in line with their obligations under National Planning Objective 37 of the National Planning Framework and which will feed into their Housing Strategies and County Development Plans. The HNDA process will require a range of historical and projected economic and housing related variables as inputs, in order to produce robust and credible estimates of the future housing need for dwellings and also categorises by tenure type required in their areas.

The work done by the ESRI will be extremely valuable in allowing the Department to move forward with our work on the HNDA project in the near term and represents an ideal synergy between research and policy. The scenarios employed in the research paper include modelling a pattern of population and housing demand consistent with achieving the objectives of the NPF. This modelling is critical to our own future work on the delivery of the NPF. The use of scenarios built around normal migration, and high and low migration have also formed part of the work, along with NPF-influenced migration. We look forward to working with local authorities to ensure that future development patterns are well informed by a coherent and consistent understanding of existing patterns and likely future needs.

We would like to thank the members of the Steering Committee for their input to this innovative modelling exercise, and in particular, the report's authors Dr Adele Bergin and Dr Abián García-Rodríguez, for their dedicated work on this paper.

Assistant Secretary Maria Graham, Planning Division of the Department of Housing, Local Government and Heritage Assistant Secretary Paul Lemass, Housing Policy, Legislation and Governance Division of the Department of Housing, Local Government and Heritage 


\section{TABLE OF CONTENTS}

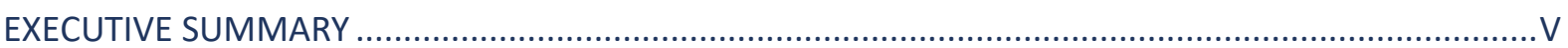

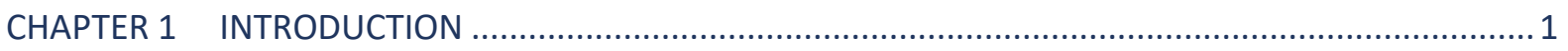

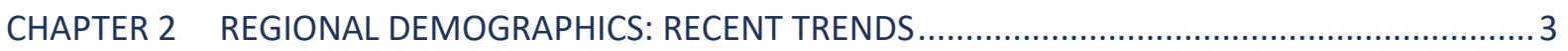

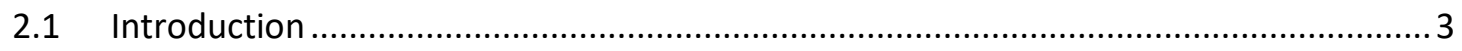

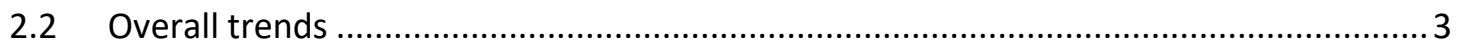

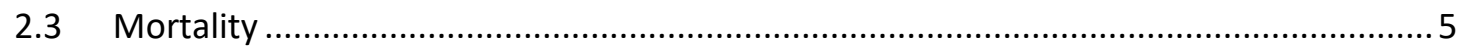

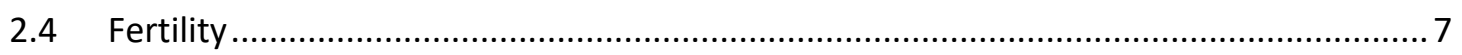

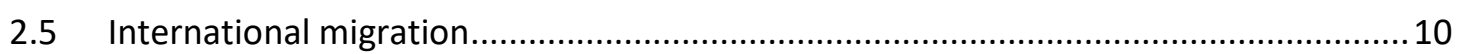

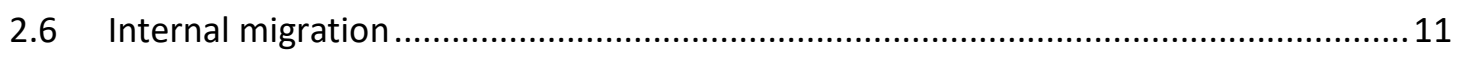

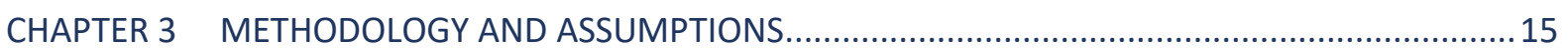

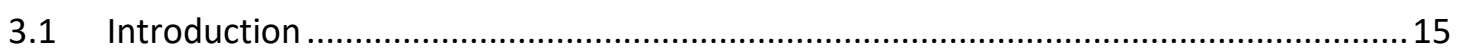

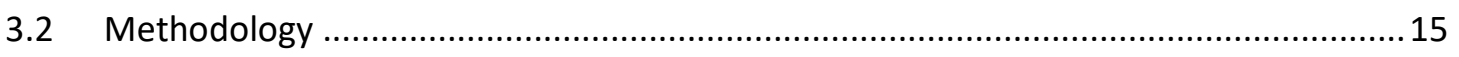

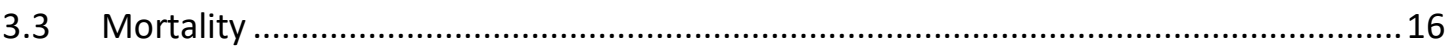

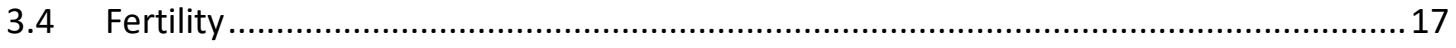

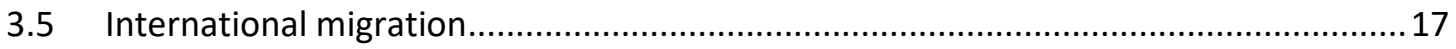

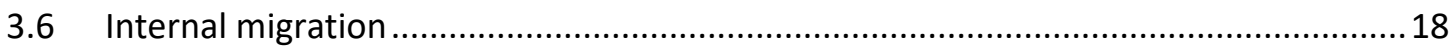

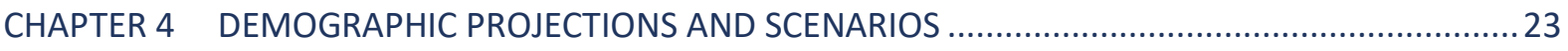

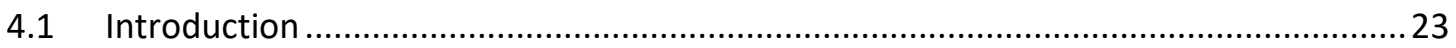

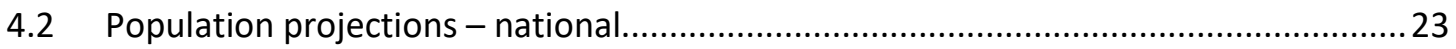

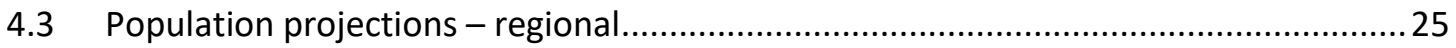

4.4 Internal migration: the 50:50 city scenario from the National Planning Framework ...28

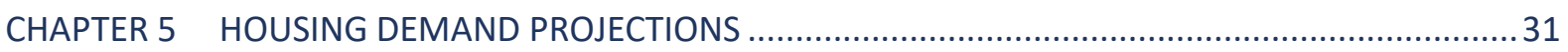

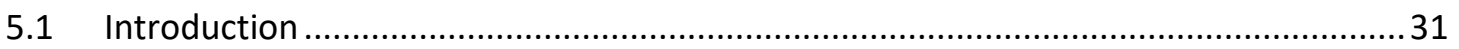

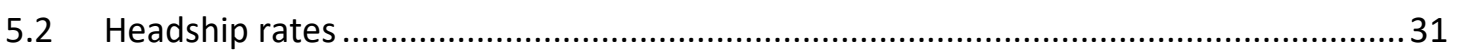

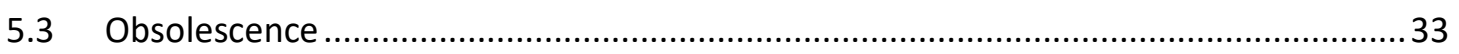

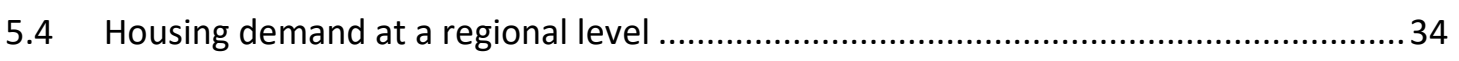

5.5 Types of housing demand - a qualitative assessment .................................................

5.6 Implications of COVID-19 pandemic on projections.......................................................

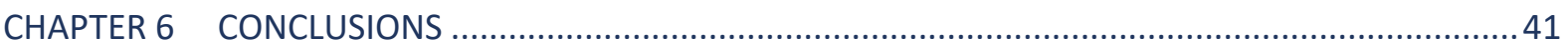

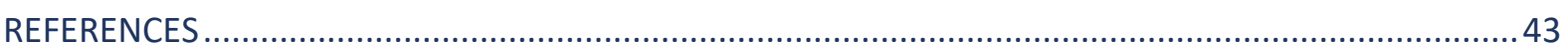

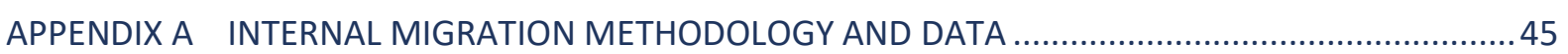

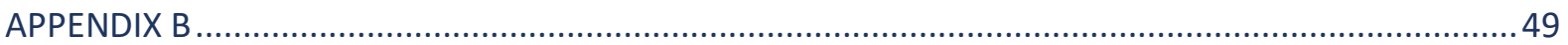




\section{LIST OF TABLES}

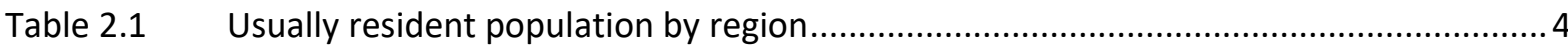

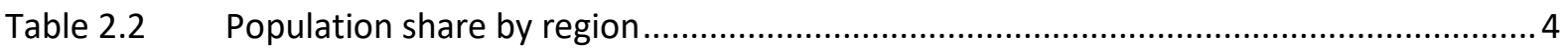

Table 2.3 Young and old dependency rate by region, 1996-2016..............................................5

Table 2.4 Deaths per 1,000 population by region, average 2007-2016 …..................................

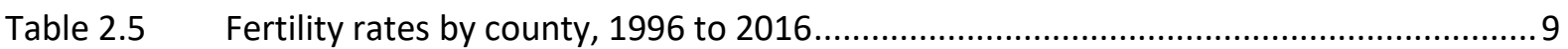

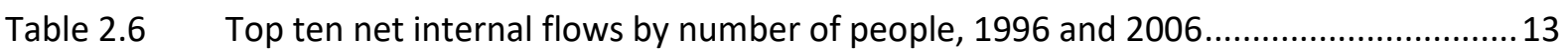

Table $3.1 \quad$ Estimation results: gross internal population flows ...................................................19

Table 3.2 County-level unemployment rates: data and projections...........................................20

Table 4.1 Comparison of assumptions between scenarios .....................................................24

Table 4.2 Population projections, annual growth rates and population shares, $2016-2040 \ldots \ldots . .26$

Table 5.1 Headship rates by five-year age group, 1996-2016; 2016 max and min ......................32

Table B.1 Usually resident population by county ........................................................................ 49

Table B.2 Population projections by county, 2016-2040 …...................................................50

Table B.3 Structural housing demand projections by local authority, 2017-2040 …...................51

\section{LIST OF FIGURES}

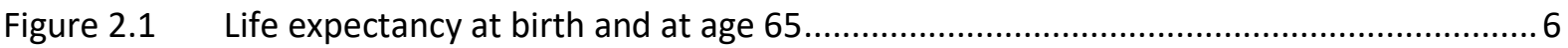

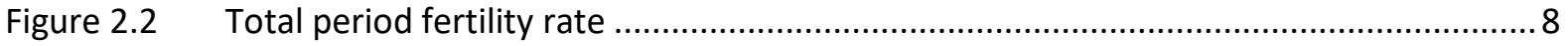

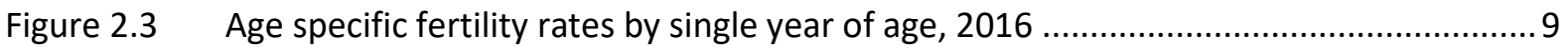

Figure 2.4 International migration flows and total population change …..................................10

Figure $2.5 \quad$ International net migration distribution by county ..................................................11

Figure 2.6 Net internal migration and top ten Intercounty net flows ......................................12

Figure 2.7 Ratio of house prices in Dublin relative to the national average ................................. 14

Figure 4.1 Total population under different scenarios, 2016-2040 ….........................................24

Figure 4.2 Population age pyramids: National 2016-2040 (population, top); Kildare and Mayo 2040 (\% of total county population, bottom) ........................................................... 27

Figure 4.3 Internal migration in 2040 under the baseline and the $50: 50$ city scenarios................30

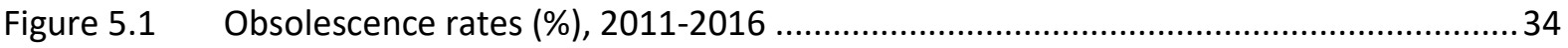

Figure 5.2 Structural housing demand: baseline, high and low migration scenarios, 2017-2040 .35

Figure 5.3 Housing demand index for the baseline and 50:50 city scenarios, 2030 .....................36

Figure 5.4 Type of accomodation by age of household reference person, 2016 ...........................38

Figure 5.5 Proportion of households in different types of housing units, 2016...........................39 
Regional housing demand, both now and in the future, has significant implications for housing policy in terms of the number of housing units required, the areas they are needed and the types of housing. This report provides estimates of structural housing demand at a local authority level out to 2040, based on regional demographic projections and projections for rates of household formation. These estimates are based on a new regional demographic model that explicitly incorporates the economic mechanisms that determine internal migration, and projections for headship rates. Our approach is to use the cohort component methodology to generate regional population projections. This method projects the population at county level by gender and single year of age for each year based on the components of population change (fertility, mortality, internal and international migration). The analysis builds on and develops previous research in this area, such as Morgenroth (2019).

The report examines a 'business as usual' scenario which is based on current trends and medium-term projections for the Irish economy. Given the uncertainty inherent in any projection exercise, the report examines a range of alternative scenarios. As international migration is the key driver of population change in Ireland, scenarios are explored that incorporate higher and lower international migration assumptions than in the 'business as usual' scenario. The assumptions underlying these scenarios draw heavily from recent trends and patterns in the data as well as findings on how certain key determinants of population change behave and react to the economic environment. The report also includes some commentary on the potential effects of the COVID-19 pandemic on these scenarios.

These types of scenarios are based on existing trends and relationships evident from data and implicitly assume that these relationships are preserved in the future. The report also considers a scenario, broadly consistent with the 50:50 City scenario developed in the National Planning Framework, where population growth is more evenly distributed between the East and Midland region and the rest of the country and where counties with larger cities attract higher inflows, and this is achieved by changing relative regional economic conditions. The differences between the 'business as usual' scenario and the 50:50 City scenario gives an indication of where policy interventions could be used to influence the spatial distribution of economic activity and ultimately the population to achieve the targets associated with the 50:50 City scenario. The population projection scenarios are then used as a key input into estimates of structural housing demand i.e. the amount of housing needed consistent with population growth at a regional level and the state of broad underlying economic conditions. 
At a national level, in the baseline scenario, the population is expected to increase by around 926,000 people between 2016 and 2040 resulting in a total population of over 5.665 million people by the end of the period. This represents significant population growth (average of 0.7 per cent per annum), which has clear implications for planning in many areas including housing. These projections are highly sensitive to international migration flows and in a high international migration scenario the total population would reach almost 6 million people by 2040 , whereas in a low international migration scenario, the population would stand at around 5.554 million people by 2040. The difference in population in 2040 compared to the baseline scenario $(+318,000$ people in the high international migration scenario and $-112,000$ in the low international migration scenario) provides a credible range for the future evolution of the population and also helps highlight the uncertainty in this type of exercise.

At a regional level, in the baseline scenario, the Eastern and Midlands region is expected to experience the fastest population growth and to capture the majority (55.6 per cent or 514,000 people) of the total expected population growth over the 2016 to 2040 period. Within this region, Dublin is expected to continue have the highest population share, although the Mid-East region, the area surrounding Dublin, is likely to experience the fastest population growth. The projection results also suggest that the slowest growing region will continue to be the Northern and Western region, showing signs of an ageing population. Overall, differences in population growth at a county level over the projection horizon to 2040 are more muted compared to the 1996 to 2016 period.

By applying county-level age-specific headship rates and incorporating expected housing obsolescence, we can convert the population projections into estimates of structural housing demand. In the baseline scenario, the level of housing demand is around 28,000 per annum over the medium term, although it is higher in the short-run given recent net international migration inflows. Housing demand in the high international migration scenario is close to 33,000 per annum and is around 26,000 per annum in the low international migration scenario. Our baseline scenario results suggest, relative to population shares, higher levels of housing demand in Dún Laoghaire-Rathdown, Cork City, Meath and Kildare and relatively lower levels of demand in Mayo and Fingal. A different regional pattern emerges in the 50:50 City scenario. More internal migration and a different distribution of international migration lead to higher increases in housing demand particularly in Limerick, but also in Cork County and Galway County, as well as to some degree in Galway City and Waterford. The higher increases in some local authorities come at the expense of lower increases in others such as Meath and Kildare whereas some local authorities would see lower housing demand over time including Kerry, Tipperary and Wexford. 


\section{CHAPTER 1}

\section{Introduction}

This report provides estimates of structural housing demand at a regional level, over the long-run, based on regional demographic projections and projections for rates of household formation. Regional housing demand, both now and in the future, has significant implications for housing policy in terms of the number of housing units required, the areas they are needed and the types of housing.

The analysis is based on a new regional demographic model which incorporates a novel treatment of internal migration, specifically where internal migration is related to economic conditions. Our approach is to use the cohort component methodology to generate regional population projections. This method projects the population at county level by gender and single year of age for each year based on the components of population change (fertility, mortality, internal and international migration). The analysis builds on and develops previous research in this area, such as Morgenroth (2018).

We examine a 'business as usual' scenario which is based on current trends and medium-term projections for the Irish economy. Given the uncertainty inherent in any projection exercise we also examine a range of alternative scenarios. As international migration is the key driver of population change in Ireland, we consider scenarios that incorporate higher and lower international migration assumptions than in the 'business as usual' scenario. Additional commentary on the potential impact of the COVID-19 pandemic on these scenarios has been included at the end of the report.

These types of scenarios are based on existing trends and relationships evident from data and implicitly assume that these relationships are preserved in the future. We also consider a scenario, broadly consistent with the 50:50 City scenario developed in the National Planning Framework, where population growth is more evenly distributed between the Eastern and Midland region and the rest of the country, and where counties with larger cities attract higher inflows and this is achieved by changing relative regional economic conditions. The differences between the 'business as usual' scenario and the 50:50 City scenario gives an indication of where policy interventions could be used to influence the spatial distribution of economic activity and ultimately the population to achieve the targets associated with the 50:50 City scenario. The population projection scenarios are then used as a key input into estimates of structural housing demand 
i.e. the amount of housing needed consistent with population growth at a regional level and the state of broad underlying economic conditions.

The remainder of the report is structured as follows: Chapter 2 provides an overview of population developments at a regional level; Chapter 3 outlines the methodology used in generating the demographic scenarios and describes the key assumptions for the drivers of population change; Chapter 4 brings together the assumptions and evidence base to generate a range of demographic scenarios; Chapter 5 draws on the analysis in the previous sections to estimate structural housing demand at a local authority level and Chapter 6 concludes. 


\section{CHAPTER 2}

\section{Regional demographics: recent trends}

\section{$2.1 \quad$ INTRODUCTION}

This section describes the evolution of the population at a regional level. It highlights trends in population growth, the spatial distribution and the age structure of the population. It then examines patterns in the drivers of population change - specifically mortality, fertility, and international and internal migration in more depth. The aim is to use the patterns evident from the data to inform assumptions on the future development of the population, particularly for the 'business as usual' scenario.

\subsection{OVERALL TRENDS}

At a national level, Ireland has experienced extremely rapid population growth in recent years, both in absolute terms and relative to other countries. Over the 20-year period 1996 to 2016, the population grew by an average of 1.3 per cent per annum compared to under 0.3 per cent per annum growth in the EU28. ${ }^{1}$ This amounts to an increase in the population of over 1.1 million between 1996 and 2016. This strong population growth has not been evenly dispersed around the country. Table 2.1 shows the population at various intervals over the 1996 to 2016 period at a NUTS 3 level ${ }^{2}$ and Appendix Table B.1 shows the data at a county level. The table shows that, over the 1996 to 2016 period, the Mid-East region experienced the highest population growth, averaging 2.2 per cent per annum, with Meath and Kildare recording the highest population growth in the region. Over the same period, the Mid-West had the lowest population growth, averaging just 0.9 per cent per annum, with Limerick and Tipperary experiencing the lowest population growth in the region. There is also substantial variation in population growth within regions, with counties such as Kerry, Mayo and Sligo having relatively lower population growth and counties such as Kildare, Meath and Laois experiencing relatively higher population growth.

Population growth slowed between 2011 and 2016 at an aggregate level, in the aftermath of the Great Recession, with particularly low growth recorded in the Border, West and Mid-West regions.

2 The regions in the table and throughout the report are based on the latest Nomenclature of Territorial Units for Statistics (NUTS) classification. The allocation of counties to their NUTS 3 regions is as follows: Dublin: county Dublin; Mid-East: Kildare, Louth, Meath and Wicklow; Midlands: Laois, Longford, Offaly and Westmeath; Border: Cavan, Donegal, Leitrim, Monaghan and Sligo; West: Galway, Mayo and Roscommon; Mid-West: Clare, Limerick and Tipperary; South-East: Carlow, Kilkenny, Waterford and Wexford; South-West: counties Cork and Kerry. 
TABLE 2.1 USUALLY RESIDENT POPULATION BY REGION

\begin{tabular}{|l|r|r|r|r|r|r|}
\hline & \multicolumn{7}{c|}{ Population ('000) } & $\begin{array}{c}\text { Annual Growth, } \\
1996-2016\end{array}$ \\
\hline & 1996 & 2002 & 2006 & 2011 & 2016 & $\%$ \\
\hline State & $3,626.1$ & $3,917.2$ & $4,232.9$ & $4,574.9$ & $4,739.6$ & 1.3 \\
\hline Eastern and Midland & $1,703.4$ & $1,862.6$ & $2,022.2$ & $2,203.0$ & $2,318.2$ & 1.6 \\
\hline Dublin & $1,058.3$ & $1,122.8$ & $1,185.2$ & $1,269.3$ & $1,341.4$ & 1.2 \\
\hline Mid-East & 439.6 & 514.4 & 585.7 & 652.1 & 685.8 & 2.2 \\
\hline Midlands & 205.5 & 225.4 & 251.3 & 281.6 & 291.0 & 1.8 \\
\hline Northern and Western & 667.5 & 711.0 & 770.1 & 834.9 & 843.7 & 1.2 \\
\hline Border & 315.1 & 330.7 & 356.5 & 390.9 & 392.6 & 1.1 \\
\hline West & 352.4 & 380.3 & 413.6 & 444.1 & 451.1 & 1.2 \\
\hline Southern & $1,255.2$ & $1,343.6$ & $1,440.6$ & $1,537.0$ & $1,577.6$ & 1.1 \\
\hline Mid-West & 392.6 & 418.7 & 443.5 & 466.4 & 471.2 & 0.9 \\
\hline South-East & 316.0 & 344.5 & 377.0 & 408.0 & 418.9 & 1.4 \\
\hline South-West & 546.6 & 580.4 & 620.1 & 662.6 & 687.5 & 1.2 \\
\hline
\end{tabular}

Source: $\quad$ CSO, Census, various issues.

The population is also unevenly distributed across regions (Table 2.2) and changes in population shares over time have been somewhat limited. The Eastern and Midland region had just under 49 per cent of the population in 2016, an increase of almost two percentage points over its 1996 share. Although Dublin dominates in terms of its population share, its share has fallen slightly over time while the population share of the Mid-East has risen by just under 2.5 percentage points between 1996 and 2016. Overall, the population share in the broader Northern and Western and Southern regions has fallen slightly with the exception of the South-East region where the population share has shown a marginal increase over time.

TABLE 2.2 POPULATION SHARE BY REGION

\begin{tabular}{|l|c|c|c|c|c|}
\hline & \multicolumn{5}{|c|}{ Population (share in each region) } \\
\hline & $\mathbf{1 9 9 6} \%$ & $\mathbf{2 0 0 2} \%$ & $\mathbf{2 0 0 6} \%$ & $\mathbf{2 0 1 1} \%$ & $\mathbf{2 0 1 6} \%$ \\
\hline State & 100.0 & 100.0 & 100.0 & 100.0 & 100.0 \\
\hline Eastern and Midland & 47.0 & 47.5 & 47.8 & 48.2 & 48.9 \\
\hline Dublin & 29.2 & 28.7 & 28.0 & 27.7 & 28.3 \\
\hline Mid-East & 12.1 & 13.1 & 13.8 & 14.3 & 14.5 \\
\hline Midlands & 5.7 & 5.8 & 5.9 & 6.2 & 6.1 \\
\hline Northern and Western & 18.4 & 18.2 & 18.2 & 18.3 & 17.8 \\
\hline Border & 8.7 & 8.4 & 8.4 & 8.5 & 8.3 \\
\hline West & 9.7 & 9.7 & 9.8 & 9.7 & 9.5 \\
\hline Southern & 34.6 & 34.3 & 34.0 & 33.6 & 33.3 \\
\hline Mid-West & 10.8 & 10.7 & 10.5 & 10.2 & 9.9 \\
\hline South-East & 8.7 & 8.8 & 8.9 & 8.9 & 8.8 \\
\hline South-West & 15.1 & 14.8 & 14.6 & 14.5 & 14.5 \\
\hline
\end{tabular}

Source: $\quad \mathrm{CSO}$, Census, various issues. 
There are also differences in the age structure of the population at a regional level. Table 2.3 shows young-age and old-age dependency rates by region. ${ }^{3}$ At a national level the old-age dependency rate has increased from 17.6 to 20.4 between 1996 and 2016, while the young-age dependency rate has fallen from 36.5 to 32.3 over the same period. In terms of regional differences, in 2016 the Northern and Western region had the highest old-age dependency rate, in particular the Border region, whereas Dublin and surrounding areas have the lowest. In the case of young-age dependency, the Mid-East and the Midlands regions registered the highest rates in 2016, with Dublin recording the lowest rate.

TABLE 2.3 YOUNG AND OLD DEPENDENCY RATE BY REGION, 1996-2016

\begin{tabular}{|l|l|l|l|l|l|l|}
\hline & \multicolumn{3}{|c}{ Old-Age Dependency Rate } & \multicolumn{3}{c}{ Young-Age Dependency Rate } \\
\hline & 1996 & 2006 & 2016 & 1996 & 2006 & 2016 \\
\hline State & 17.6 & 16.1 & 20.4 & 36.5 & 29.7 & 32.3 \\
\hline Eastern and Midland & 15.0 & 14.1 & 18.0 & 35.0 & 28.7 & 31.6 \\
\hline Dublin & 14.6 & 14.5 & 17.9 & 32.3 & 25.7 & 28.2 \\
\hline Mid-East & 14.2 & 12.4 & 17.3 & 39.2 & 32.9 & 36.8 \\
\hline Midlands & 19.5 & 16.5 & 20.0 & 40.3 & 33.5 & 36.3 \\
\hline Northern and Western & 22.5 & 19.0 & 23.9 & 39.6 & 31.4 & 33.6 \\
\hline Border & 22.6 & 19.5 & 24.3 & 40.7 & 33.0 & 35.1 \\
\hline West & 22.5 & 18.7 & 23.6 & 38.6 & 29.9 & 32.4 \\
\hline Southern & 18.6 & 17.4 & 22.4 & 37.2 & 30.4 & 32.6 \\
\hline Mid-West & 18.8 & 17.4 & 22.8 & 37.6 & 30.5 & 32.6 \\
\hline South-East & 18.3 & 17.3 & 22.6 & 38.1 & 32.1 & 34.1 \\
\hline South-West & 18.8 & 17.5 & 22.0 & 36.3 & 29.4 & 31.7 \\
\hline
\end{tabular}

Source: CSO, Census, various issues.

\section{$2.3 \quad$ MORTALITY}

Over the course of the twentieth century and into this century, the Irish population has experienced significant improvements in mortality. ${ }^{4} \mathrm{~A}$ measure related to mortality is the period expectation of life at birth, which is the average number of years a new-born would live for, based on prevailing mortality rates for that year. This is shown for males and females in Figure 2.1. The graph shows strong improvements in mortality for both males and females over, broadly, the first 60 years of the twentieth century and then continued improvement, albeit at a diminished pace from the 1960s to today. The graph also reveals gender

3 The young-age dependency ratio is the ratio of the number of young people at an age when they are normally economically inactive (under 15 years old) compared to the working age population (those aged 15 to 64), while the old-age dependency ratio refers to those the number of older people at an age when they are generally economically inactive (over 65 years old) compared to the working age population.

$4 \quad$ Assumptions on mortality rates (by age and gender and year) are used in developing the population projections. These assumptions are also used to calculate summary measures of the mortality level of a population, such as life expectancy at birth. 
differences in life expectancy, although this gap has narrowed somewhat in more recent years. In 2015, male life expectancy at birth was 79.3 years while the comparable figure for females was 83.3 years. Although the data show improvements in life expectancy over time, the data for the most recent years reveal a slight slowdown in the rate of improvement.

Changes in life expectancy over time are driven by complex interactions of economic, social, institutional and health factors and it is difficult to unpick the role of each in shaping changes in mortality. Much of the initial improvement in mortality in the first half of the twentieth century is attributable to improvements in infant and child mortality rates to low levels by the end of the 1950s (CSO, 2013). This means that further improvements in infant and child mortality have only a limited impact on the expectation of life at birth. The rate of improvement in mortality from the 1960 s to 1980 s was at a slower pace and increases in the incidence of deaths of people of working age from most forms of cancer and ischaemic heart disease are considered to be the main contributing factors to this pattern (CSO, 2013). From the 1990s, mortality rates began to decrease more rapidly with improvements in all age groups, especially for those in older age groups (see period life expectancy at age 65 in Figure 2.1) most likely attributable to advances in medical care, rising incomes and lifestyle factors (CSO, 2013).

\section{FIGURE 2.1 LIFE EXPECTANCY AT BIRTH AND AT AGE 65}

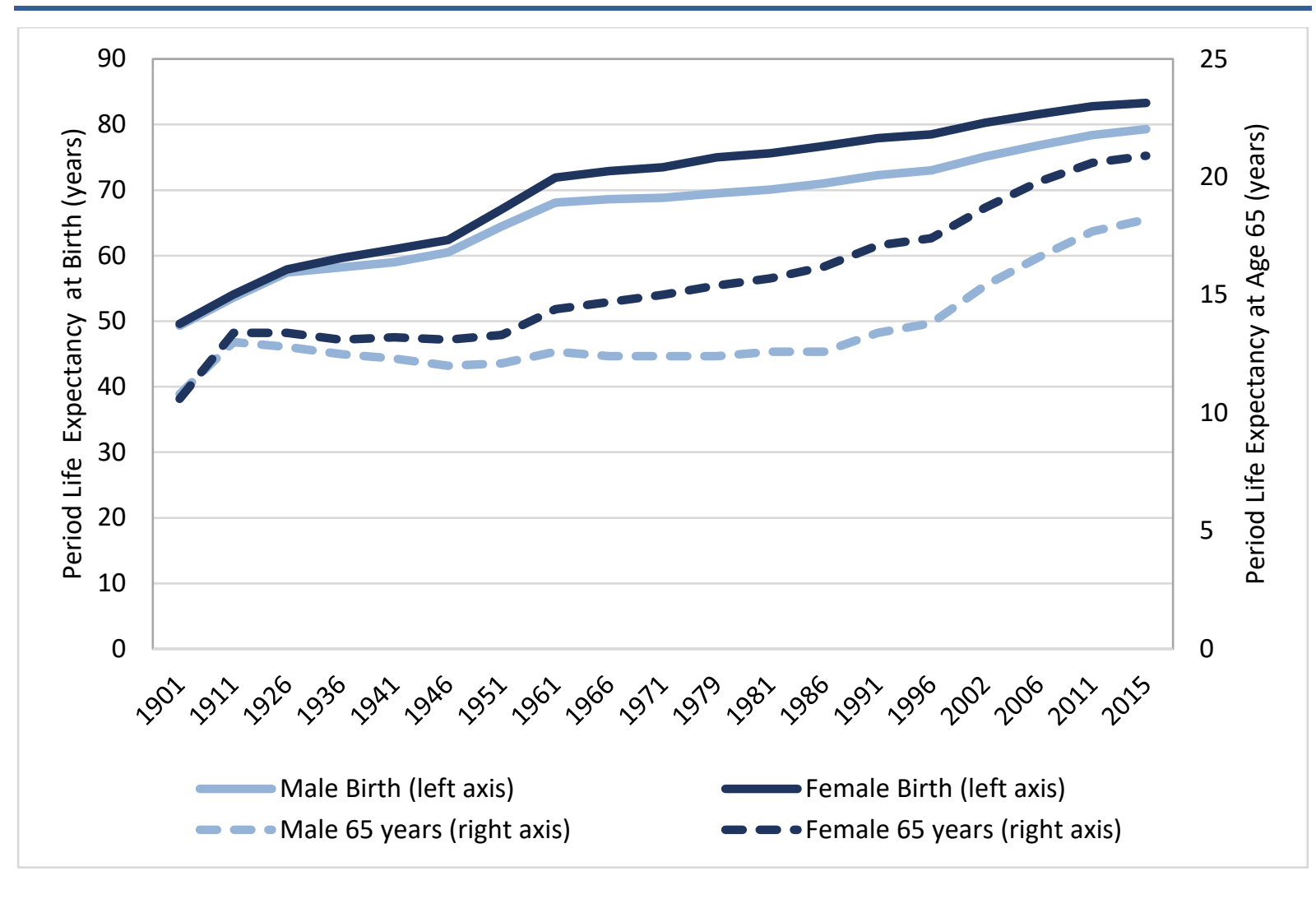


Other research has shown that there are some differences in mortality rates associated with certain characteristics. For example, people living in affluent areas, those in higher social classes, married persons, those with higher levels of education and owner occupiers all tend to have lower mortality rates (CSO, 2019a). Therefore, we might also expect mortality rates to differ at a county level. However this level of disaggregated data is not available. Despite this, we would still expect to see differences in mortality (i.e. the number of deaths) across counties depending on the age distribution within counties. Table 2.4 shows the number of deaths per thousand of population at a national level and across the NUTS3 regions broken down by age group. The data show that the number of deaths increases with age (except for the youngest age cohort) and that the number of deaths essentially increases exponentially with age for the older age groups. The Table also reveals some differences across regions with fewer (more) deaths per thousand population than the national average in the Mid-East (Mid-West).

TABLE 2.4 DEATHS PER 1,000 POPULATION BY REGION, AVERAGE 2007-2016

\begin{tabular}{|l|c|c|c|c|c|c|c|c|c|c|c|}
\hline & $\begin{array}{c}\text { All } \\
\text { ages }\end{array}$ & $\begin{array}{c}\mathbf{0 - 4} \\
\text { years }\end{array}$ & $\begin{array}{c}\mathbf{5 - 1 4} \\
\text { years }\end{array}$ & $\begin{array}{c}\mathbf{1 5 - 2 4} \\
\text { years }\end{array}$ & $\begin{array}{c}\mathbf{2 5 - 3 4} \\
\text { years }\end{array}$ & $\begin{array}{c}\mathbf{3 5 - 4 4} \\
\text { years }\end{array}$ & $\begin{array}{c}\mathbf{4 5 - 5 4} \\
\text { years }\end{array}$ & $\begin{array}{c}\mathbf{5 5 - 6 4} \\
\text { years }\end{array}$ & $\begin{array}{c}\mathbf{6 5 - 7 4} \\
\text { years }\end{array}$ & $\begin{array}{c}\mathbf{7 5 - 8 4} \\
\text { years }\end{array}$ & $\begin{array}{c}\mathbf{8 5 +} \\
\text { years }\end{array}$ \\
\hline State & 6.3 & 0.8 & 0.1 & 0.4 & 0.6 & 1.0 & 2.5 & 6.3 & 16.4 & 49.8 & 157.3 \\
\hline Mid-East & 4.7 & 0.8 & 0.1 & 0.4 & 0.5 & 0.8 & 2.1 & 5.7 & 15.5 & 50.0 & 149.8 \\
\hline Dublin & 5.9 & 0.8 & 0.1 & 0.3 & 0.5 & 1.1 & 2.7 & 6.6 & 16.5 & 47.6 & 151.1 \\
\hline Midlands & 6.2 & 0.8 & 0.1 & 0.4 & 0.6 & 0.9 & 2.2 & 5.9 & 15.8 & 50.8 & 168.8 \\
\hline South-East & 6.8 & 0.9 & 0.1 & 0.5 & 0.7 & 1.1 & 2.5 & 6.2 & 16.5 & 50.7 & 158.8 \\
\hline South-West & 6.8 & 0.9 & 0.1 & 0.5 & 0.6 & 1.1 & 2.6 & 6.2 & 16.7 & 50.7 & 160.2 \\
\hline Border & 6.9 & 0.8 & 0.1 & 0.4 & 0.6 & 1.0 & 2.3 & 6.2 & 16.1 & 49.8 & 157.6 \\
\hline West & 7.0 & 0.8 & 0.1 & 0.4 & 0.6 & 1.0 & 2.4 & 6.1 & 15.8 & 49.1 & 153.4 \\
\hline Mid-West & 7.3 & 1.1 & 0.1 & 0.5 & 0.7 & 1.1 & 2.6 & 6.7 & 18.1 & 53.9 & 174.1 \\
\hline
\end{tabular}

Source: CSO, Vital Statistics.

\section{$2.4 \quad$ FERTILITY}

The total fertility rate (a measure of the number of children that a representative woman will have over her lifetime $)^{5}$ at a national level declined significantly from the early 1980s from over 3 to just under 2 by the mid-1990s and has remained broadly stable since then (see Figure 2.2). ${ }^{6}$ The data also show differences in fertility rates at a regional level. For example, Dublin generally has the lowest fertility rate over time and the gap between the rate in Dublin and the national average shows no sign of converging over time.

Specifically, the total period fertility rate represents the theoretical average number of children who would be born alive to a woman during her lifetime if she were to pass through her child bearing years (ages 15-49) conforming to the age specific rates of a given year. The rate refers to a theoretical female cohort.

6 This is below the replacement level (the level of fertility at which a population exactly replaces itself from one generation to the next) of 2.1 children per woman. 


\section{FIGURE 2.2 TOTAL PERIOD FERTILITY RATE}

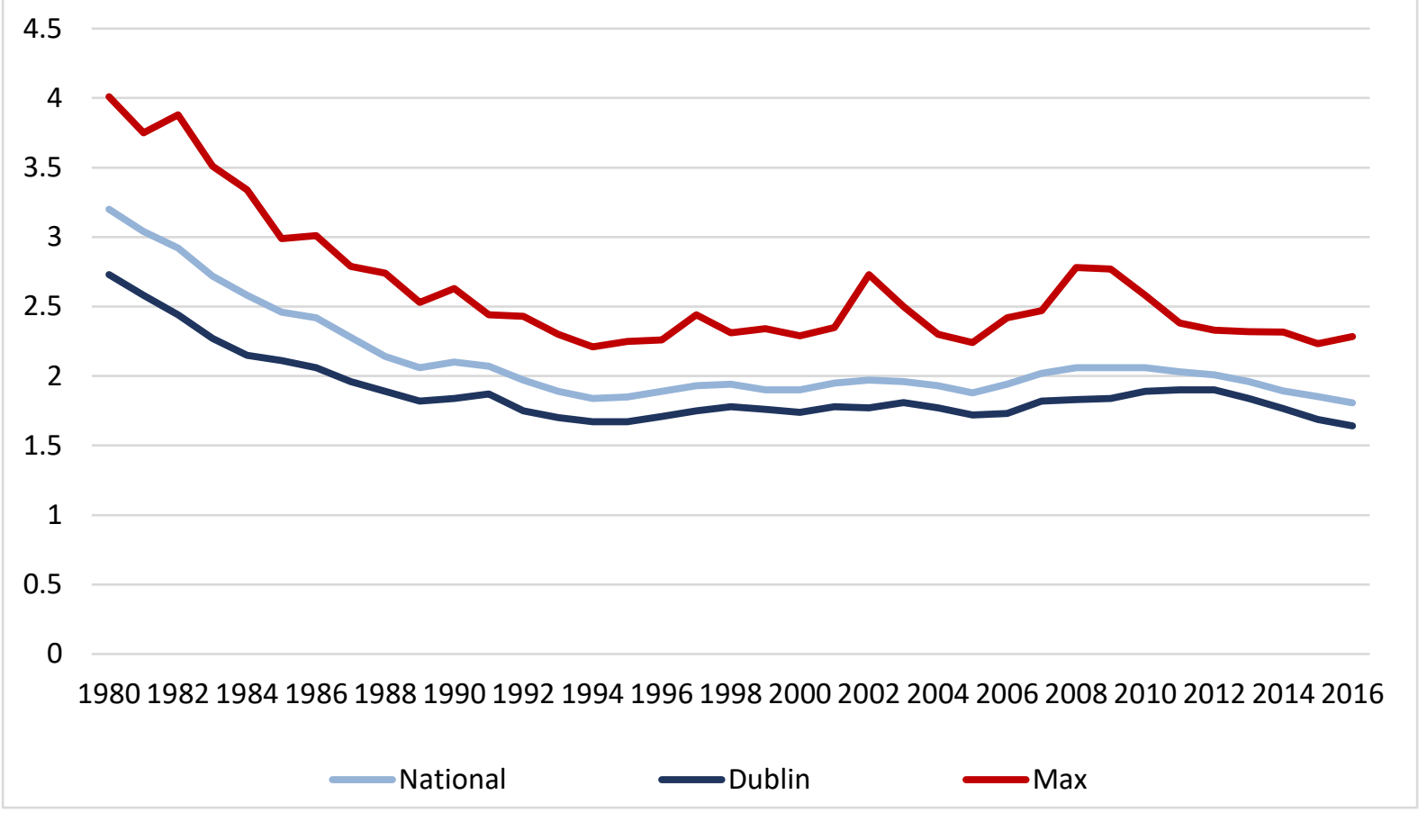

Source: $\quad$ CSO, Vital Statistics.

Table 2.5 shows county-level fertility rates over time. The table shows there is a lot of variation in fertility rates across counties. For example, in 2016 while the national total fertility rate was 1.81 , the range was from 1.64 in Dublin to 2.28 in Longford. The tables reveal that these differences in fertility rates across counties persist over time so that individual counties tend to consistently have either high or low fertility rates.

There are also differences in fertility by age of women. Figure 2.3 shows the prevailing age-specific fertility rates by year of age for women. The age-specific fertility rate measures the annual number of births to women of a specified age per 1,000 women of that age. The graph indicates that fertility rates increase steadily with age and they peak between ages 31-35 before falling sharply for women beyond this age group. 


\section{TABLE 2.5 FERTILITY RATES BY COUNTY, 1996 TO 2016}

\begin{tabular}{|c|c|c|c|c|c|c|c|c|c|c|c|c|c|c|c|c|c|c|c|c|c|}
\hline & & & & & & & & & & & & & & & & & & & & & \\
\hline Dublin & 1.71 & 1.75 & 1.78 & 1.76 & 1.74 & 1.78 & 1.77 & 1.81 & 1.77 & 1.72 & 1.73 & 1.82 & 1.83 & 1.84 & 1.89 & 1.90 & 1.90 & 1.84 & 1.76 & 1.69 & 64 \\
\hline erry & 90 & 96 & 91 & 84 & 84 & 88 & 1.95 & & 1.90 & 1.81 & 1.93 & 2.05 & 00 & 10 & 87 & 01 & 93 & 84 & 78 & 75 & 1.81 \\
\hline Ian & 96 & 38 & 91 & 96 & 77 & 71 & & 31 & 75 & 1.87 & 1.80 & 1.95 & 2.03 & 1.94 & 2.03 & 01 & 2.00 & 2.03 & 1.94 & .96 & 1.93 \\
\hline Ike & 1.86 & 93 & 92 & 83 & 1.91 & 1.99 & 1.97 & 1.96 & 1.90 & 1.85 & 1.87 & 1.94 & 2.07 & 2.04 & 2.08 & 2.03 & 2.02 & 1.94 & 91 & 78 & .72 \\
\hline igo & 94 & 2 & 2 & 34 & 34 & 8 & 32 & 5 & 1 & 2 & 1 & 2.04 & 2.08 & 2 & 9 & 01 & 21 & 34 & 87 & 84 & .83 \\
\hline ork & 39 & 94 & 99 & 83 & 85 & 1.88 & 5 & 1.90 & 1.90 & 1.88 & 1.96 & 2.01 & 2.07 & 2.10 & 2.08 & 2.02 & 1.99 & 1.95 & 1.87 & 88 & .75 \\
\hline IW & 39 & 01 & כ7 & 02 & 03 & 10 & 6 & 1.94 & 1.93 & 1.87 & 1.86 & 1.96 & 2.07 & 1.96 & 2.01 & 1.96 & 2.01 & 1.96 & 1.85 & .81 & 1.83 \\
\hline n & 15 & 11 & 05 & 10 & 95 & 3 & 0 & 2 & & 91 & 5 & 98 & 2.00 & 2.07 & 94 & 96 & 7 & 37 & 88 & 91 & 93 \\
\hline me & 5 & 08 & 06 & 93 & 87 & 1.81 & 1.87 & 1.95 & 1.86 & 1.81 & 1.94 & 2.04 & 2.11 & 2.16 & 2.13 & 2.09 & 2.00 & 1.97 & 1.94 & 1.97 & 1.89 \\
\hline $\mathrm{Sc}$ & 82 & 90 & 93 & 77 & 68 & 32 & 5 & 1.89 & 8 & 2.06 & 2.01 & 2.04 & 2.27 & 2.27 & 2.28 & 02 & 10 & 21 & 99 & 1.92 & 1.93 \\
\hline uth & 1.88 & 99 & 33 & 05 & 10 & 2.30 & 06 & 1.92 & 1.92 & 1.83 & 1.97 & 1.93 & 2.04 & 1.94 & 2.00 & 1.99 & 09 & 2.24 & 98 & 2.05 & 1.99 \\
\hline ate & 1.99 & 1.94 & 90 & 92 & 93 & 2.09 & 2.21 & 2.09 & 2.06 & 1.97 & 2.18 & 2.18 & 2.27 & 2.15 & 2.14 & 2.15 & 2.04 & 2.09 & 2.06 & 1.99 & 1.97 \\
\hline$f$ fal & 10 & 07 & 22 & 8 & 35 & 3 & & 2. & 2 & 2. & 2.09 & 2.09 & 14 & 2 & 5 & 3 & 9 & 8 & 18 & 94 & .98 \\
\hline ayo & 11 & 2.12 & 15 & 09 & 2.09 & 2.09 & 2.01 & 2.00 & 1.93 & 2.00 & 2.10 & 2.25 & 2.21 & 2.10 & 2.15 & 2.13 & 2.17 & 2.19 & 2.06 & 1.99 & 2.02 \\
\hline pper & 09 & 15 & 4 & 9 & 12 & 1.98 & 1.97 & 2.04 & 2.04 & 2.11 & 2.04 & 2.26 & 2.2 & 2.34 & 2 & 2 & 2 & 4 & 14 & 99 & 2.05 \\
\hline /icklow & 2.01 & 96 & Do & 03 & 02 & 2.03 & 2.16 & 2.07 & 2.09 & 1.92 & 2.21 & 2.28 & 2.32 & 2.30 & 2.35 & 2.18 & 2.19 & 2.13 & 2.05 & 2.02 & 1.96 \\
\hline are & 2.01 & 2.16 & 08 & 27 & 2.08 & 2.19 & 2.34 & 2.26 & 2.16 & 2.10 & 2.16 & 2.15 & 2.18 & 2.28 & 2.03 & 2.08 & 2.08 & 1.89 & 1.88 & 2.03 & 1.96 \\
\hline aois & 2.00 & 2.07 & 10 & 06 & 2.04 & 2.15 & 2.26 & 2.30 & 2.30 & 2.04 & 2.11 & 2.37 & 2.42 & 2.50 & 2.50 & 2.12 & 2.03 & 1.94 & 1.95 & 1.96 & 1.84 \\
\hline West & 2.13 & 14 & 11 & 26 & 2.29 & 33 & 2.19 & 2.17 & 2.14 & 2.10 & 2.22 & 2.13 & 2.16 & 2.17 & 2.16 & 2.11 & 2.11 & 2.14 & 2.15 & 2.00 & 2.03 \\
\hline Kildar & 2.09 & 2.14 & 18 & 07 & 2.27 & 2.31 & & 2. & 2.20 & 2.00 & 2.16 & 2.31 & 2.29 & 2.32 & 2.29 & 2.16 & 2.11 & 02 & 2.02 & 1.97 & 1.93 \\
\hline Leitrim & 2.09 & 05 & 10 & 20 & 02 & 92 & 29 & 2.26 & 2.25 & 2.21 & 2.17 & 2.45 & 2.50 & 2.38 & 2.27 & 2.15 & 2. & 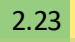 & .00 & 2.11 & 2.17 \\
\hline Meath & 1.98 & 05 & 99 & 04 & 09 & 35 & 2.20 & 2.33 & 2.28 & 2.22 & 2.16 & 2.41 & 2.39 & 2.35 & 2.39 & 2.33 & 2.14 & 2.21 & 2.08 & 1.99 & 1.99 \\
\hline Wexf & 2. & 2.16 & 19 & 24 & 99 & & & & 2.27 & 2.20 & 2.26 & 2.29 & 2.44 & 2.29 & 2.18 & 2.20 & 2.17 & 2.05 & 2.13 & 2.05 & 1.95 \\
\hline Carlow & 2.06 & 1.84 & 16 & 98 & 2.22 & 2.24 & 2.40 & 2.33 & 2.14 & 2.16 & 2.21 & 2.47 & 2.59 & 2.36 & 2.35 & 2.38 & 30 & 09 & 2.32 & 02 & 1.90 \\
\hline var & 2.18 & 44 & 21 & 34 & 10 & 14 & 2.19 & 2.09 & 2.16 & 2.14 & 2.29 & 2.33 & 2.60 & 2.52 & 2.49 & 2.38 & 2.29 & 2.22 & 2.08 & 2.09 & 2.12 \\
\hline n & 2.26 & 27 & 31 & 20 & 20 & 2.35 & & 2. & ? & 2. & 2.42 & 8 & 2.78 & 2.77 & 2.58 & 2. & 2. & 2.3 & 2.16 & .23 & .28 \\
\hline
\end{tabular}

Sources: $\quad$ CSO and Department of Health.

\section{FIGURE 2.3 AGE SPECIFIC FERTILITY RATES BY SINGLE YEAR OF AGE, 2016}

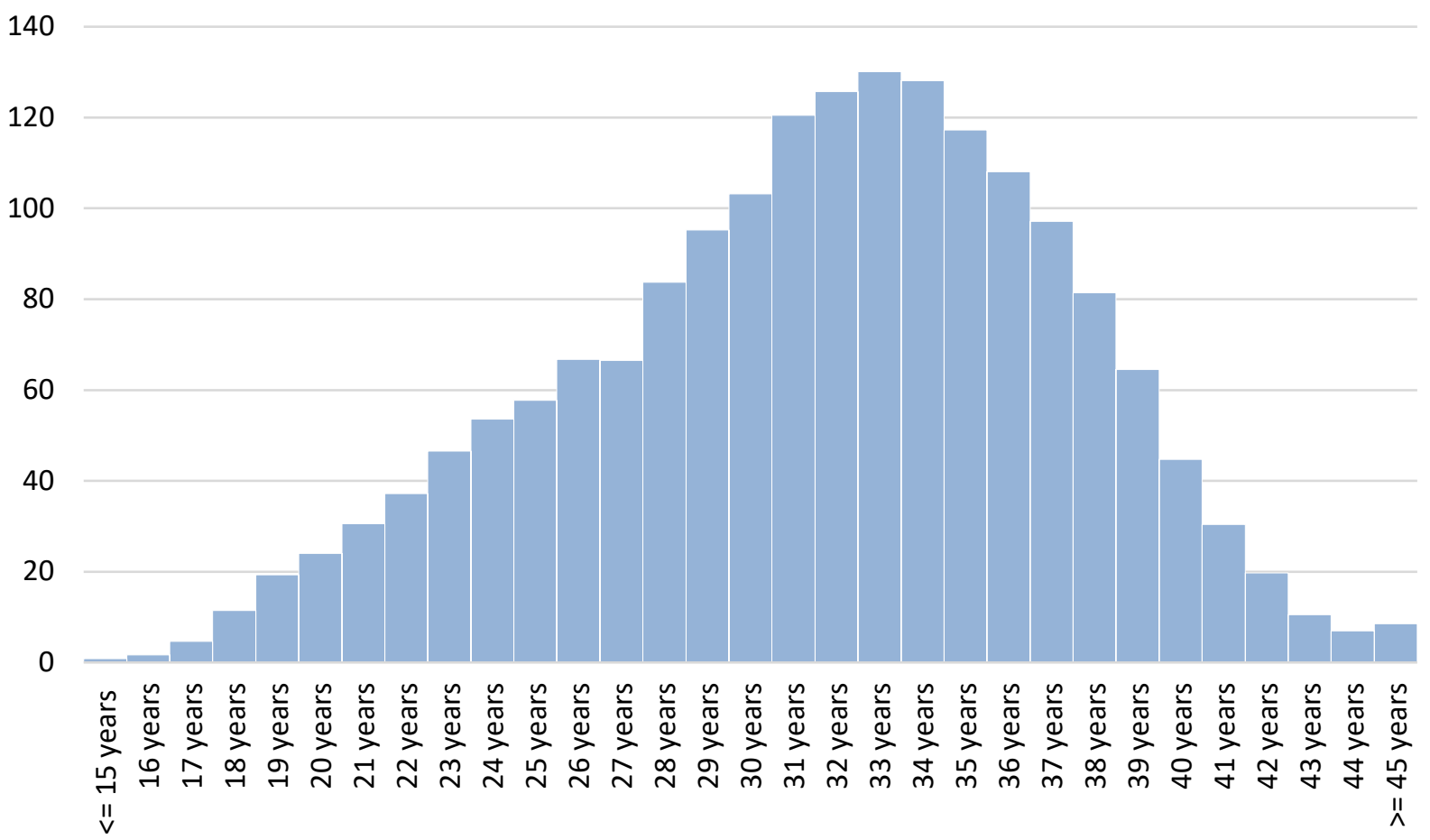

Source: $\quad$ CSO, Vital Statistics

Notes: The age specific fertility rate for a particular year of age is the number of live births to women of that age per 1,000 females of the same year of age. 


\section{$2.5 \quad$ INTERNATIONAL MIGRATION}

International migration has long been the key driver of population change in Ireland. These flows in and out of Ireland tend to be very volatile and are highly sensitive to economic conditions both domestically and internationally (in the source countries for immigrants or the destination countries for emigrants). ${ }^{7}$ Figure 2.4 shows these flows in recent years. The graph highlights the close relationship between net migration and population change. It also demonstrates the variability in migration flows from one year to the next. In the second half of the 1990s, strong economic growth and a tight labour market encouraged net inflows into the country and these net inflows accelerated and were particularly strong following the enlargement of the EU in 2004. The Great Recession led to a sharp reversal of the trend in net immigration and Ireland experienced net outflows from 2010 to 2014. Following the economic recovery, net inflows re-emerged in 2015 and have been increasing in more recent years.

\section{FIGURE 2.4 INTERNATIONAL MIGRATION FLOWS AND TOTAL POPULATION CHANGE}

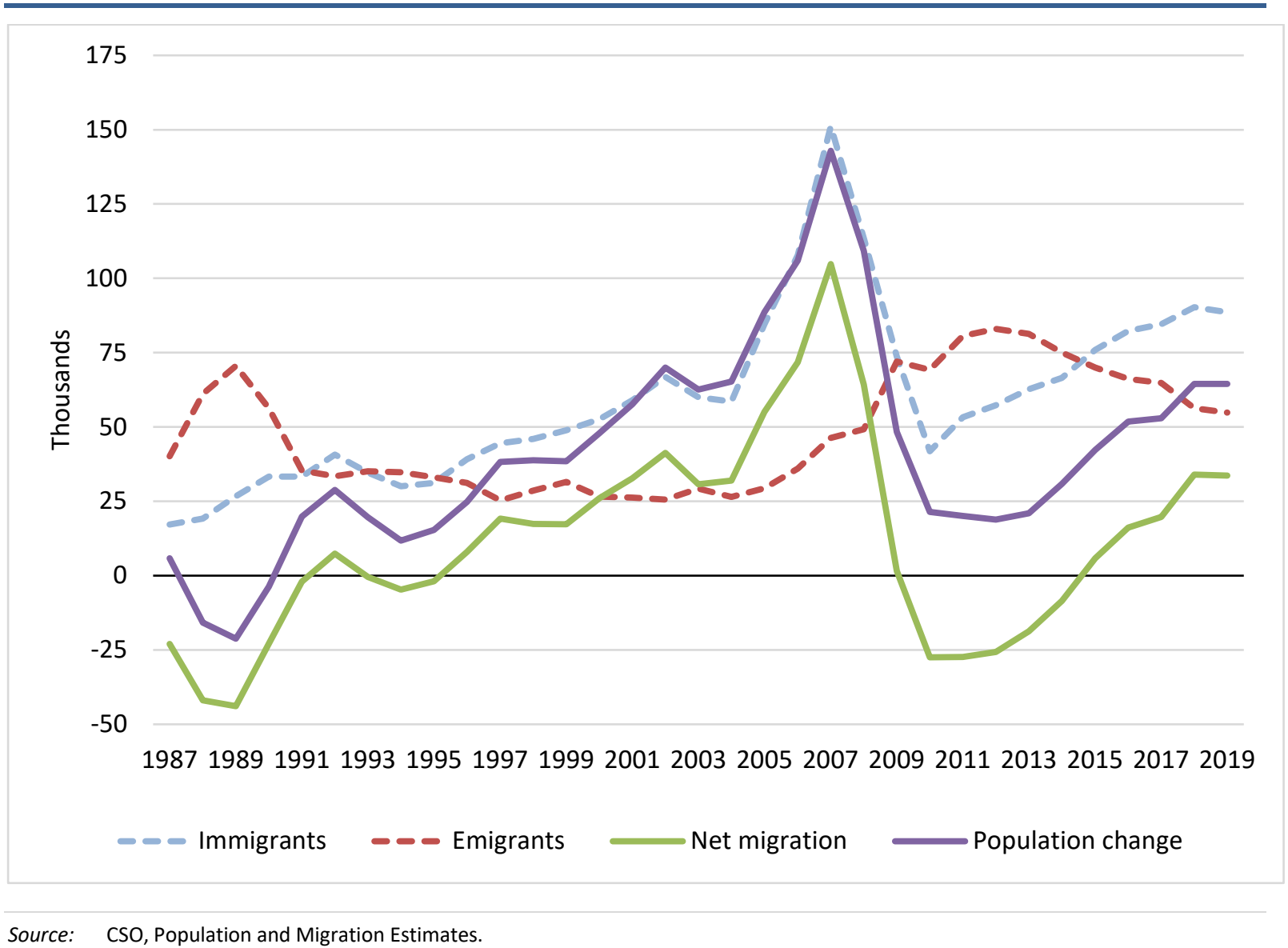

Figure 2.5 shows the spatial distribution of international migrants. The spatial distribution of international migrants has remained broadly stable and is highly concentrated in certain counties. Five counties comprise the destination for over 
two-thirds of international migrants with Dublin attracting just under 44 per cent of international migrants. In terms of the age distribution of migrants, most are of prime working age with around 47 per cent between the ages of 20 and 30 and a further 27 per cent between the ages of 31 and 45 .

\section{FIGURE 2.5 INTERNATIONAL NET MIGRATION DISTRIBUTION BY COUNTY}

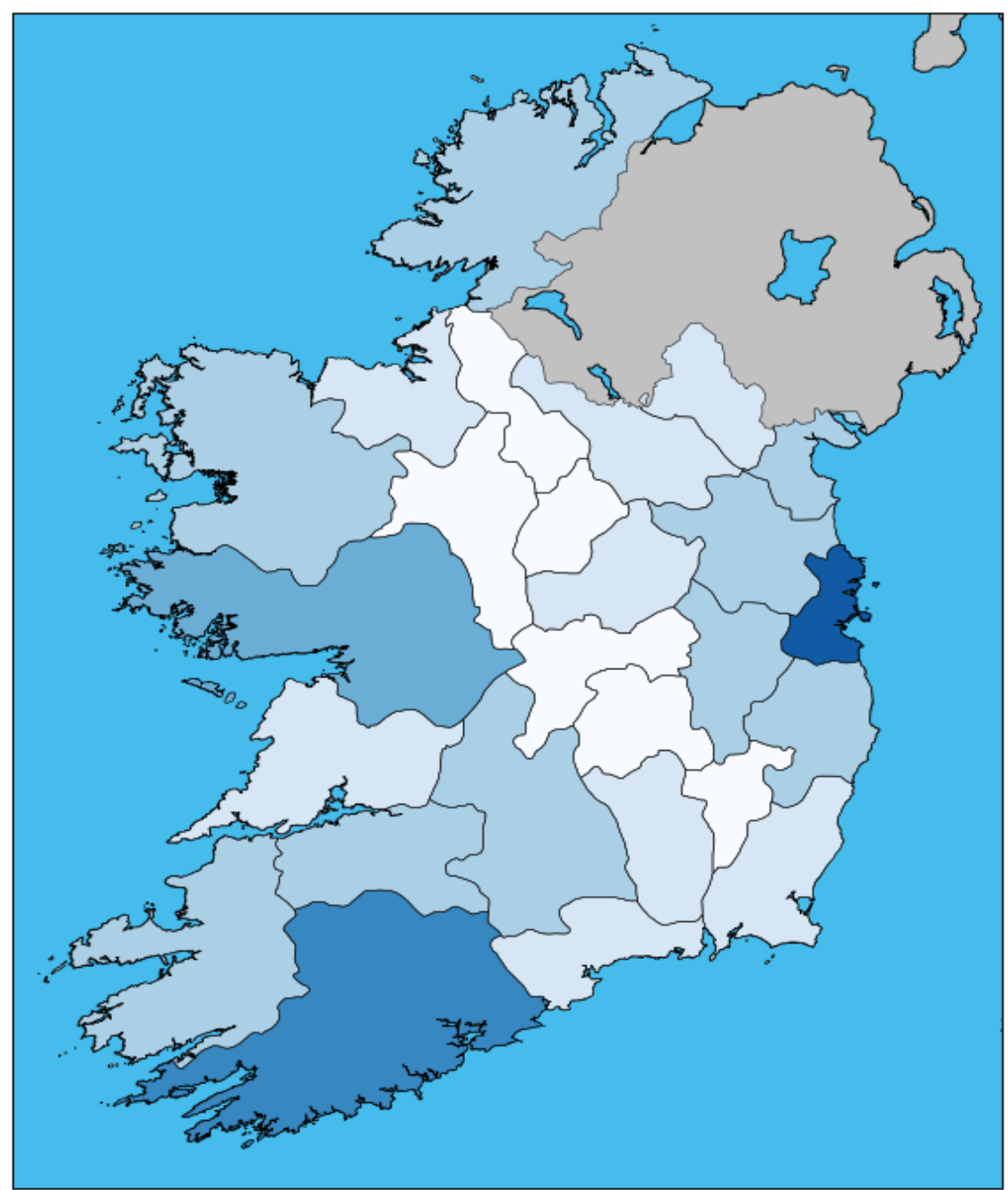

\begin{tabular}{|l|r|}
\hline Dublin & $43.6 \%$ \\
\hline Cork & $10.9 \%$ \\
\hline Galway & $5.8 \%$ \\
\hline Kildare & $3.7 \%$ \\
\hline Limerick & $3.3 \%$ \\
\hline Donegal & $2.8 \%$ \\
\hline Meath & $2.6 \%$ \\
\hline Wicklow & $2.3 \%$ \\
\hline Kerry & $2.3 \%$ \\
\hline Mayo & $2.1 \%$ \\
\hline Tipperary & $2.0 \%$ \\
\hline Louth & $2.0 \%$ \\
\hline Clare & $1.8 \%$ \\
\hline Waterford & $1.8 \%$ \\
\hline Wexford & $1.8 \%$ \\
\hline Westmeath & $1.7 \%$ \\
\hline Kilkenny & $1.3 \%$ \\
\hline Cavan & $1.2 \%$ \\
\hline Monaghan & $1.1 \%$ \\
\hline Sligo & $1.1 \%$ \\
\hline Laoighis & $0.9 \%$ \\
\hline Roscommon & $0.9 \%$ \\
\hline Offaly & $0.8 \%$ \\
\hline Carlow & $0.8 \%$ \\
\hline Longford & $0.7 \%$ \\
\hline Leitrim & $0.5 \%$ \\
\hline & \\
\hline
\end{tabular}

Source: $\quad$ CSO, Census data.

Note: The table shows the average of the 2011 and 2016 county distributions.

\section{6}

INTERNAL MIGRATION

The remaining element that determines regional demographics is internal migration. Understanding the determinants of internal migration for a country like Ireland is crucial especially given the instability in the pattern of population flows between regions in the last 30 years (see, for example, CSO, 2019b). We can observe the evolution of intercounty population movements using Census data. As the Census asks respondents for current residence and residence one year previously, we can track how many people moved from one county to another in a given year. This reveals two very different internal migration patterns for the 
Census years of 1991, 1996 and 2011 compared to the Census years 2002, 2006 and 2016.

Figure 2.6 shows the patterns observed in the years 1996 and 2006, which provide illustrative examples of the two different internal migration patterns for those years, where the counties in the figure are shaded by the sign and magnitude of net internal migration registered for that year. Counties shaded in blue had positive internal migration for that year, receiving more population from other counties than the population that left to reside in another county while the opposite holds for the counties shaded in red. In addition, the map shows the top ten net internal migration flows for the two years, indicated by the arrows on the map and presented in Table 2.6, and the difference between the two patterns is stark. In 1996, the major net gainers were the main cities and the Greater Dublin Area. The largest internal migration flows were from the main population centres to Dublin and from Dublin to the counties contiguous to Dublin. In contrast, in 2006 Dublin registered significant net internal outflows, with more than 10,000 people leaving to reside in some other county than people moving to Dublin from other counties. The top ten net flows are flows out of Dublin, with the population moving to counties which are either contiguous to Dublin or are connected to Dublin via motorway.

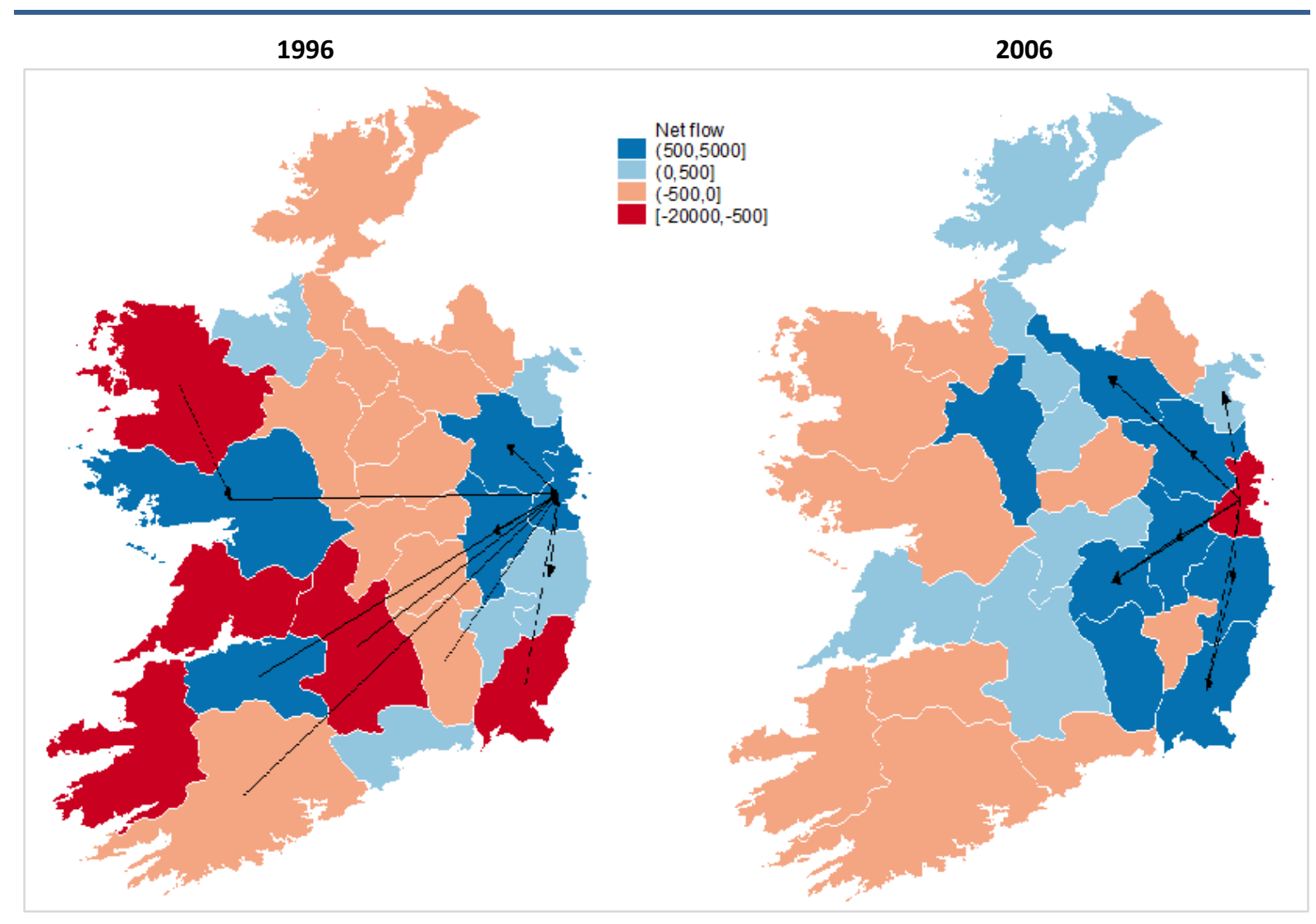


TABLE 2.6 TOP TEN NET INTERNAL FLOWS BY NUMBER OF PEOPLE, 1996 AND 2006

\begin{tabular}{|c|c|c|c|}
\hline \multicolumn{2}{|c|}{1996} & \multicolumn{2}{|c|}{2006} \\
\hline Dublin to Kildare & 1,127 & Dublin to Meath & 3,534 \\
\hline Dublin to Meath & 758 & Dublin to Kildare & 2,301 \\
\hline Cork to Dublin & 696 & Dublin to Wicklow & 1,718 \\
\hline Dublin to Wicklow & 401 & Dublin to Wexford & 788 \\
\hline Limerick to Dublin & 367 & Dublin to Laois & 695 \\
\hline Kilkenny to Dublin & 302 & Wicklow to Wexford & 475 \\
\hline Galway to Dublin & 281 & Dublin to Cavan & 470 \\
\hline Tipperary to Dublin & 261 & Dublin to Louth & 450 \\
\hline Wexford to Dublin & 246 & Kildare to Laois & 406 \\
\hline Mayo to Galway & 231 & Meath to Cavan & 394 \\
\hline
\end{tabular}

Source: Authors' calculations based on CsO, Census data.

The analysis of the flow patterns demonstrates that movements in and out of Dublin are the key element in determining the overall internal migration scenario. In turn, these movements are consistent with regional economic developments such as the evolution of the housing market in Dublin compared to the rest of the country. Figure 2.7 shows the ratio of new house prices in Dublin relative to the national average, with the years preceding the censuses highlighted in blue when Dublin was a net gainer of internal migration and red when it was a net loser. The graph shows this ratio is lower (more moderate house prices in Dublin relative to the national average) in the years where Dublin is a net gainer of internal migration (1991, 1996 and 2011), whereas the ratio is higher (much higher house prices in Dublin relative to the national average) in the years where Dublin experiences greater population outflows (2002, 2006 and 2016). As expected, the population reacts to underlying economic conditions, such as house prices in this case, creating the observed internal migration flows. 


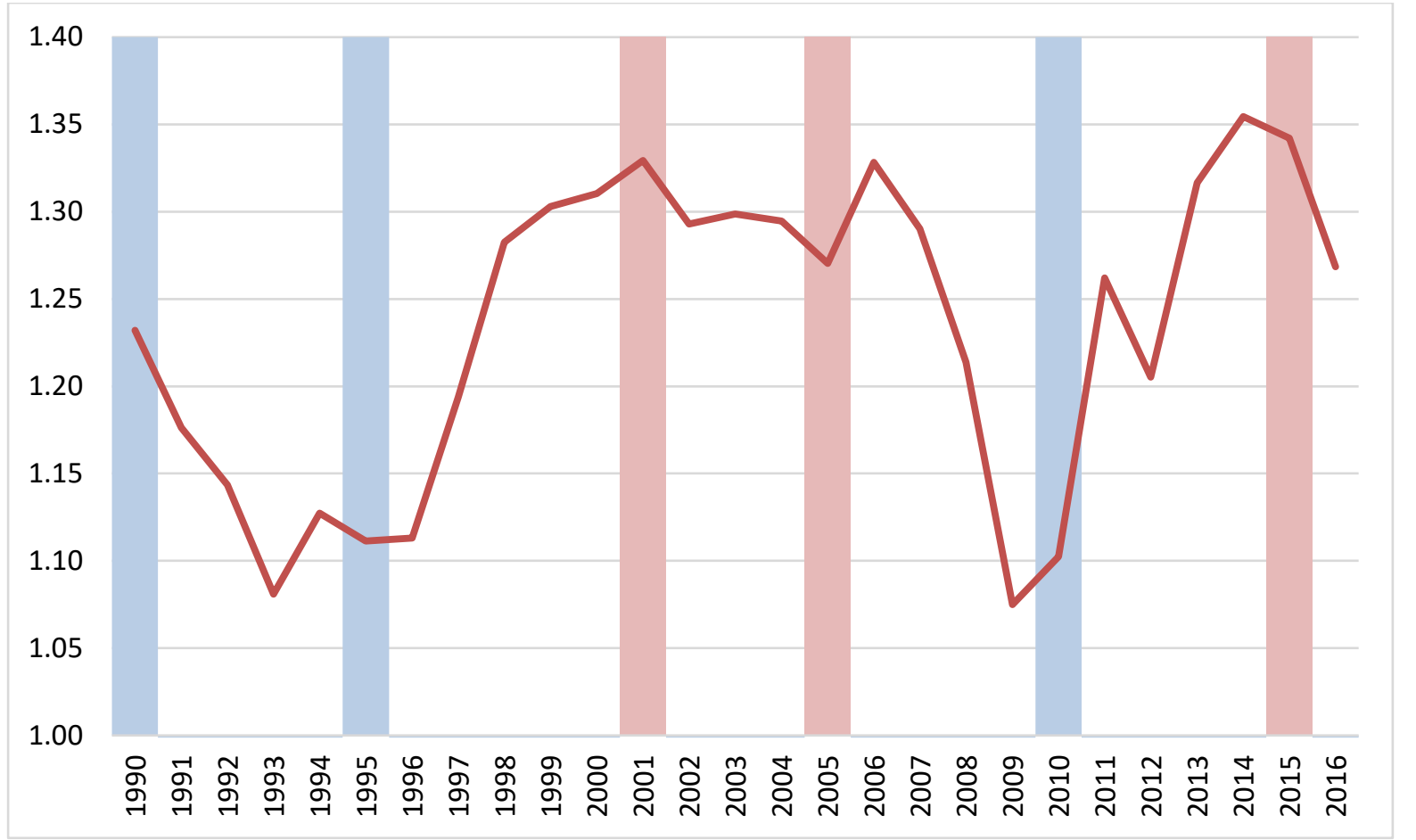

Source: Department of Housing, Local Government and Heritage. 


\section{CHAPTER 3}

\section{Methodology and assumptions}

\section{$3.1 \quad$ INTRODUCTION}

This section provides an overview of the cohort-component methodology which is the broad framework used to generate the population projections and scenarios. It then outlines the key assumptions on mortality, fertility and migration that are needed to generate demographic projections. The existing trends outlined in the previous section are used to inform these assumptions. This section also describes the methodology and results for the new model of internal migration that has been incorporated into the regional demographic model. Together with projections for the underlying economic conditions at county level, this produces an estimate of the future pattern of internal migration in Ireland, providing closure to our demographic model.

\subsection{METHODOLOGY}

We use the cohort-component method, the most widely used methodology, to produce population projections. This method follows two simple equations to generate the population aged i for county $j$ at time $t$ :

$$
\begin{gathered}
P_{t}^{i, j}=\left(1-d_{t-1}^{i-1}\right) * P_{t-1}^{i-1, j}+n E M_{t}^{i, j}+n I M_{t}^{i, j}, \text { for } \mathrm{i}>0 \\
P_{t}^{0, j}=B_{t}^{j}+n E M_{t}^{0, j}+n I M_{t}^{0, j}
\end{gathered}
$$

The first equation shows the population aged $\mathrm{i}$ in county $\mathrm{j}, P_{t}^{i, j}$, in a given year is simply the surviving population $\left(1-d_{t-1}^{i-1}\right)$, where $d_{t-1}^{i-1}$ is the age-specific mortality rate, that was one year younger the previous year $\left(P_{t-1}^{i-1, j}\right)$ plus net international $\left(n E M_{t}^{i, j}\right)$ and internal migration $\left(n I M_{t}^{i, j}\right)$ of the population aged i. The second equation is for the population aged less than 1 , so instead of the surviving population it uses the number of births in the county $B_{t}^{j}$. To produce population projections with this method we need assumptions for mortality rates, births and international and internal migration.

We have developed this standard methodology in an innovative way. For internal migration, instead of simply assuming a particular behaviour/pattern for internal migration, we estimate the determinants of internal migration in Ireland and incorporate these results into our regional demographic model. We use regression analysis based on historical data to determine the intensity of the relationship between internal migration and different determinants like economic conditions and house prices, which we then combine with projections of these determinants to create a projection of internal migration. This improves population projections 
in two ways. Firstly, we do not have to arbitrarily choose which of the two internal migration patterns described in Section 2.6 is more likely to happen in the future. Instead, we create baseline projections for the underlying economic conditions at county level consistent with broad national macroeconomic projections (Bergin et al., 2016) ${ }^{8}$ and then let these determinants shape the future pattern of internal migration. Second, by making internal migration a function of economic conditions, we can generate alternative scenarios where economic conditions change and see how the new pattern of internal migration, and therefore population at a regional level, evolves. As mentioned earlier, the fact that economic conditions can be influenced by policy interventions, allows for the opportunity to model the effects of policy on the distribution of population in Ireland.

This element is vitally important for multi-regional demographic models as it works as a balancing element within the model, with internal migration able to respond to changes in underlying economic conditions. As such, policy interventions aimed at altering the regional distribution of population would operate through the internal migration channel, by changing underlying economic conditions to make a region relatively more attractive through, for example, higher employment or lower house prices.

\subsection{MORTALITY}

Given the historical trends in life expectancy described in Section 2.3 , it is expected that there will be continued improvements over the projection horizon. We follow the mortality assumptions of the recent CSOs national and regional projections (see CSO, 2018 and CSO, 2019b). Essentially an age and gender specific profile of mortality rates is developed for the projection horizon and these rates are applied at a county level. This means that any variation in mortality at a county level will be driven by differences in the age structure of that county. A 'targeting' method is adopted whereby it is assumed that short-term rates of improvement in mortality (at each age and for both genders) will slowly converge to common long-term rates of improvement (at each age and for both genders) by the target year (assumed to be the 25th year of the projections). ${ }^{9}$ Mortality rates for males and females up to the age of 90 are assumed to improve at 2.5 per cent and 2.0 per cent per annum respectively. These short-term rates of improvement are assumed to decline linearly over a 25-year period to a long-term rate of 1.5 per cent per annum for both males and females. It was assumed that there would be no mortality improvements at age 100 years and upwards. For those aged between 
90 and 100, the annual rate of improvement is generated by interpolating between the assumed rate of improvement at 90 years and 100 years. This implies a projected increase in life expectancy at birth for males from 79.3 years in 2015 to 84.3 years in 2041 and for females from 83.3 in 2015 to 87.1 years in 2041. ${ }^{10}$

\subsection{FERTILITY}

Based on the trends described in Section 2.4, the overall total fertility rate (TFR) is assumed to decrease from 1.8 in 2016 to 1.6 in 2031 and remain constant thereafter. This profile matches the 'low variant' or F2 assumption used by the CSO (see CSO, 2018 and CSO, 2019b) in their population projections. Starting with county-level TFRs, the reduction in the overall TFR is applied proportionally to all counties. This ensures the national pattern shown in Table 2.4 is maintained over the projection horizon (i.e. counties that historically have had higher TFRs will continue to have comparatively higher TFRs over the projection horizon and vice versa). In a similar way, age specific fertility rates are adjusted proportionally with the headline decline of the overall TFR and applied to each county so that the ASFRs add up to their projected TFR. ${ }^{11}$

\subsection{INTERNATIONAL MIGRATION}

Given the volatility associated with international migration flows and the inherent uncertainty associated with projections of international migration, we include three different sets of assumptions. The impact of the different assumptions on the projected population profile and age structure will also highlight the sensitivity of population projections to changes in the flows of international migrants. All three scenarios start in 2020 and incorporate the most recent CSO estimates (CSO, 2019c) ${ }^{12}$ of international migration. The three sets of assumptions are:

- Baseline/'business as usual': net international migration declines linearly from $+33,700$ in 2019 to $+15,000$ by 2024 and remains constant thereafter. The medium-term figure is based on projections from the Economic Outlook (see Bergin et al., 2016) and is consistent with expected economic conditions in Ireland and abroad. ${ }^{13}$

10 In comparison with the mortality projections used in previous analysis such as CSO (2013) and Morgenroth (2018), these projections represent a slowdown in the rate of improvement of mortality rates. The previous projections were generated after the 2011 Census and assumed life expectancy at birth to be 86.5 years for males and 88.2 years for females by the year 2041.

11 With data by single year of age, the TFR is simply the sum of all age-specific fertility rates (ASFR).

12 The latest CSO estimates of net international migration for 2017, 2018 and 2019 are $+19,800,+34,000$ and $+33,700$ respectively.

13 In COSMO, migration is determined by the relative attractiveness of Ireland to alternative labour markets. For example, if the returns to working in Ireland disimprove relative to those abroad (lower relative real after-tax earnings in Ireland), there will be a tendency for outflows to occur. Similarly, poorer employment opportunities in Ireland relative to abroad (higher relative unemployment rate in Ireland) will also lead to outflows. The level of migration implied by projections from COSMO is fed into the demographic model. 
- High migration: net international migration of $+30,000$ in 2020 and remaining constant thereafter. This assumption is consistent both with recent data (CSO, 2019c) and with the 'high population growth' scenario in Wren et al. (2017) and the M1 net inward migration from the recent CSO projections (CSO, 2018 and CSO, 2019b).

- Low migration: net international migration drops to $+5,000$ by 2022 and adjusts towards the baseline scenario over the following five years.

\subsection{INTERNAL MIGRATION}

To produce projections for internal migration we combine estimation results from a model of migration flows between counties with projections for the underlying economic determinants of internal migration. Using data from the 2011 and 2016 Censuses the flows between counties are modelled as a function of four key variables: the distance in kilometres between the counties, if the counties are contiguous, house prices in the origin county and the differences in labour market conditions between the counties. ${ }^{14}$ Differences in labour market conditions are captured in a variable expressing the ratio of expected incomes. Expected income is defined as disposable income per capita multiplied by one minus the unemployment rate (to capture differences in employment opportunities) so a county becomes more attractive when either wages go up and/or unemployment goes down. Therefore, workers consider not only how high relative wages are, but also how likely they are to get a job. Some additional dummy variables are included to account for factors such as commuting and unobserved county-level characteristics. Commuting is an important element, as some workers may decide to simply commute to their workplace instead of moving to the workplace's county, so failing to account for this can bias the results. ${ }^{15}$ The various other sets of dummy variables included have the goal of controlling both for unobserved county-level characteristics that could influence the decision to move out or into the county, as well as potential changes in a given third/other county that could affect the flow between any two counties (such as an increase in house prices in Wicklow affecting the number of people that move from Dublin to Kildare). ${ }^{16}$ The regression results are shown in Table 3.1. ${ }^{17}$ would predict a much larger migration flow between these counties due to relatively higher wages in Dublin, but in reality many workers choose simply to commute instead of moving to Dublin. These dummy variables help keep the predicted flow closer to its actual value and so capture the effect of commuting.

16 A full technical description of the methodology and data used is in Appendix B.

17 All variables are in logs, so the coefficients can be interpreted as elasticities. The explanatory variables are also lagged to avoid reverse causality issues. 
TABLE 3.1 ESTIMATION RESULTS: GROSS INTERNAL POPULATION FLOWS

\begin{tabular}{|c|c|c|c|}
\hline \multicolumn{4}{|c|}{ Gross internal flow by population at origin (log) } \\
\hline VARIABLES & (1) & (2) & (3) \\
\hline \multirow[t]{2}{*}{ Log distance km. } & $-0.704 * * *$ & $-1.516 * * *$ & $-1.520 * * *$ \\
\hline & $(0.074)$ & $(0.060)$ & $(0.060)$ \\
\hline \multirow[t]{2}{*}{ Contiguity } & $1.435^{* * *}$ & $0.911 * * *$ & $0.967 * * *$ \\
\hline & $(0.098)$ & $(0.069)$ & $(0.068)$ \\
\hline \multirow[t]{2}{*}{ Exp. wage ratio (d/o) } & $3.085 * * *$ & 0.519 & 0.521 \\
\hline & $(0.388)$ & $(0.430)$ & $(0.431)$ \\
\hline \multirow[t]{2}{*}{ Log house price (origin) } & $0.495 * * *$ & $0.517 * * *$ & $0.517^{* * *}$ \\
\hline & $(0.104)$ & $(0.142)$ & $(0.143)$ \\
\hline \multirow[t]{2}{*}{ Constant } & $-4.010 * * *$ & -1.508 & -1.510 \\
\hline & $(1.303)$ & $(1.699)$ & $(1.705)$ \\
\hline Origin dummies & No & Yes & Yes \\
\hline Destination-time dummies & No & Yes & Yes \\
\hline Commuting dummies & No & No & Yes \\
\hline CD test & 0.111 & -0.033 & -0.115 \\
\hline ( $p$-value) & $(0.912)$ & $(0.974)$ & $(0.908)$ \\
\hline Observations & 1,293 & 1,293 & 1,293 \\
\hline R-squared & 0.47 & 0.86 & 0.87 \\
\hline
\end{tabular}

The table presents the results from three specifications: column (1) shows the results without the county-level fixed effects or the commuting dummies, column (2) includes the fixed effects but not the commuting variables and column (3) presents the full preferred specification. The estimates are consistent with the theoretical model. Distance and contiguity, used as proxies for the cost of moving, have the expected sign: greater distances reduce migration flows between two counties while contiguity increases it. The expected wage ratio, although not significant in the preferred specification, has the correct sign. An increase in expected wages in the destination county (or a decrease in the origin county), holding everything else constant, increases internal migration. The estimated coefficient implies that a 1 per cent increase in expected wage in the destination county, caused by an increase in disposable income and/or a decrease in the unemployment rate, increases the migration flow between counties by 0.52 per cent. More importantly, the sign of the estimated coefficient on house prices in the origin county is positive and highly significant. An increase in house prices in the origin county makes it relatively less attractive and so increases the outflows to other counties. The estimates indicate that a 1 per cent increase in house prices in the origin county increases the migratory flow out of the county by 0.52 per cent. Finally, the results for the Pesaran CD test suggest that our controls work and so 
the flows between two counties are just a function of what is happening in those two countries, and not in some other neighbouring county. ${ }^{18}$

TABLE 3.2 COUNTY-LEVEL UNEMPLOYMENT RATES: DATA AND PROJECTIONS

\begin{tabular}{|c|c|c|c|c|c|c|c|c|}
\hline & 2001 & 2006 & 2011 & 2016 & 2021 & 2026 & 2031 & 2036 \\
\hline Cork & 4.3 & 4.1 & 13.3 & 6.9 & 4.5 & 4.5 & 4.5 & 4.5 \\
\hline Meath & 3.5 & 3.7 & 14.6 & 7.3 & 4.8 & 4.8 & 4.8 & 4.8 \\
\hline Kildare & 3.3 & 3.5 & 14.5 & 7.4 & 4.8 & 4.8 & 4.8 & 4.8 \\
\hline Dublin & 4.5 & 5.0 & 13.8 & 7.5 & 4.8 & 4.8 & 4.8 & 4.8 \\
\hline Galway & 4.9 & 4.9 & 14.8 & 7.8 & 5.0 & 5.0 & 5.0 & 5.0 \\
\hline Clare & 4.1 & 4.3 & 15.2 & 8.1 & 5.2 & 5.2 & 5.2 & 5.2 \\
\hline Kerry & 4.8 & 4.9 & 15.8 & 8.1 & 5.3 & 5.3 & 5.3 & 5.3 \\
\hline Wicklow & 4.3 & 4.5 & 15.7 & 8.3 & 5.3 & 5.3 & 5.3 & 5.3 \\
\hline Kilkenny & 4.1 & 4.2 & 15.7 & 8.3 & 5.3 & 5.3 & 5.3 & 5.3 \\
\hline Roscommon & 3.8 & 3.5 & 15.7 & 8.4 & 5.4 & 5.4 & 5.4 & 5.4 \\
\hline Monaghan & 5.3 & 4.3 & 16.7 & 8.5 & 5.6 & 5.6 & 5.6 & 5.6 \\
\hline Sligo & 4.7 & 4.2 & 14.7 & 9.1 & 5.4 & 5.4 & 5.4 & 5.4 \\
\hline Mayo & 5.7 & 5.1 & 15.8 & 9.3 & 5.6 & 5.6 & 5.6 & 5.6 \\
\hline Limerick & 4.7 & 5.1 & 16.8 & 9.3 & 5.8 & 5.8 & 5.8 & 5.8 \\
\hline Leitrim & 4.6 & 4.5 & 16.4 & 9.4 & 5.8 & 5.8 & 5.8 & 5.8 \\
\hline Tipperary & 4.6 & 4.5 & 16.1 & 9.5 & 5.8 & 5.8 & 5.8 & 5.8 \\
\hline Cavan & 4.2 & 4.6 & 17.1 & 9.8 & 6.0 & 6.0 & 6.0 & 6.0 \\
\hline Laois & 5.3 & 4.2 & 17.3 & 10.0 & 6.1 & 6.1 & 6.1 & 6.1 \\
\hline Waterford & 5.5 & 5.6 & 17.5 & 10.0 & 6.2 & 6.2 & 6.2 & 6.2 \\
\hline Westmeath & 4.6 & 4.6 & 17.1 & 10.3 & 6.2 & 6.2 & 6.2 & 6.2 \\
\hline Offaly & 4.7 & 4.8 & 18.8 & 10.4 & 6.5 & 6.5 & 6.5 & 6.5 \\
\hline Wexford & 5.6 & 5.2 & 19.4 & 10.8 & 6.7 & 6.7 & 6.7 & 6.7 \\
\hline Louth & 7.1 & 6.2 & 19.3 & 10.8 & 6.7 & 6.7 & 6.7 & 6.7 \\
\hline Carlow & 5.1 & 5.2 & 18.8 & 11.1 & 6.7 & 6.7 & 6.7 & 6.7 \\
\hline Donegal & 8.3 & 7.3 & 21.2 & 11.7 & 7.3 & 7.3 & 7.3 & 7.3 \\
\hline Longford & 5.4 & 6.4 & 20.0 & 12.7 & 7.5 & 7.5 & 7.5 & 7.5 \\
\hline National & 4.7 & 4.8 & 15.4 & 8.4 & 5.3 & 5.3 & 5.3 & 5.3 \\
\hline
\end{tabular}

Source: CSO and authors' calculations.

In addition to the estimation results, we need projections for house prices, disposable incomes and unemployment rates, all at a county level, to generate projections of internal flows. For unemployment rates, we begin with a national projection which is used to anchor the county-level projections. The national projection is based on short-term projections from the Autumn 2019 Quarterly Economic Commentary which are then linked to longer term projections from the Economic Outlook. At a county level, unemployment rates are adjusted in line with the national projections, while maintaining county-level differences that are

18 In technical terms, we fail to reject the null hypothesis that the errors are weakly cross sectional dependent, opposed to the alternative hypothesis of strong cross sectional dependency. 
apparent over time (see Table 3.2); specifically, the ratios between the countylevel unemployment rates are kept constant at their 2016 levels. Table 3.2 provides a summary of the historical county-level unemployment rates and their projections.

A similar approach is adopted for county incomes. At a national level, the shortrun projections are taken from the Autumn 2019 Quarterly Economic Commentary (McQuinn et al., 2019) which has disposable income per person projected to grow at 3.6 per cent in both 2019 and 2020. Over the longer term, county incomes are linked to projections from the Economic Outlook (Bergin et al., 2016), which project annual average disposable income growth of 2.5 per cent. County incomes are projected following the national figures, but with a small adjustment in the growth rates to take account of the differences in growth in the years for which we have county incomes data (2000 to 2016). The adjustment is small enough so as to not to change the ranking of counties in terms of disposable income per person.

Finally, for county house prices, we use recent estimates of disposable incomehouse price elasticities (Kostarakos et al., forthcoming). As before, we use the national elasticity and the national disposable income projection to create a national house price projection. County house prices are then projected to grow at the same rate as the national rate, but we adjust the house price growth projection of the counties that have statistically different elasticities than the national figure. 



\section{CHAPTER 4}

\section{Demographic projections and scenarios}

\subsection{INTRODUCTION}

This section draws together the assumptions described in the previous section to produce a range of population projections; specifically, we examine a baseline/'business as usual' scenario, a high international migration scenario, a low international migration scenario and a scenario consistent with the projections presented on the 50:50 City scenario from Morgenroth (2018), ${ }^{19}$ described below.

\subsection{POPULATION PROJECTIONS - NATIONAL}

In the Baseline/'business as usual' scenario, the population is expected to increase by 926,000 between 2016 and 2040 resulting in a total population of over 5.665 million people by the end of the period. This implies overall population growth of 0.7 per cent on an annual average basis, a significant slowdown with respect to the 1.3 per cent annual average growth during the 1996 to 2016 period. As shown in Figure 4.1, the baseline national projection for 2040, is close to that in Morgenroth (2018), denoted in the figure as ' $\mathrm{M} 18^{\prime} .{ }^{20}$ Relative to CSO (2018), the baseline projection is between the M2F2 scenario, which has 5.710 million people by 2040, and the M3F2 scenario, with 5.413 million. The difference is accounted for by the net international migration assumption $(+15,000$ per annum in the medium-run) which is the mid-point between the M2 (+20,000 per annum) and M3 $(+10,000$ per annum) in CSO (2018). Table 4.1 shows a comparison of the assumptions from all the scenarios described. population projections, in which an extra 25 per cent 'headroom' factor is added to accommodate additional needs from the Local Authorities.

20 The small difference $(+30,000$ people in 2040 compared to Morgenroth, 2018) is largely explained by differences in international migration; the Baseline projections here incorporate the robust net inflow of migrants between 2016 and 2019 and have a slightly higher medium-term assumption. The higher net international migration contained in this scenario compensates for the lower assumption for fertility and the slower rate of improvement in mortality, which results in both projections coming closer towards the end of the projection window. 


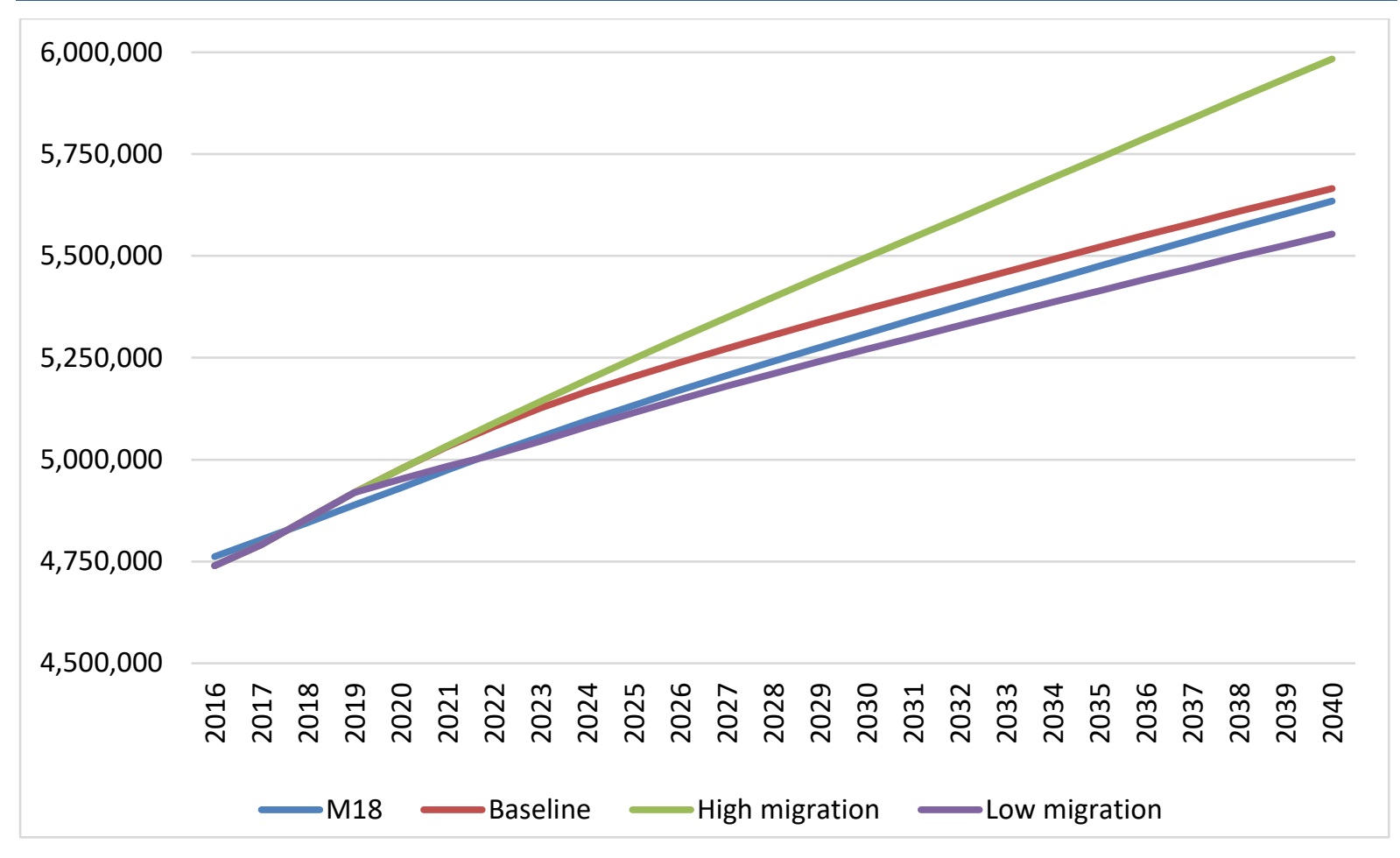

Source: Authors' calculations.

TABLE 4.1 COMPARISON OF ASSUMPTIONS BETWEEN SCENARIOS

\begin{tabular}{|c|c|c|c|}
\hline & Long-run net international migration & Mortality projections & $\begin{array}{c}\text { Fertility } \\
\text { projections }\end{array}$ \\
\hline Baseline & $+15,000$ per annum & \multirow{5}{*}{$\begin{array}{c}\text { CSO projections } \\
\text { based on latest Life } \\
\text { Tables (LT) }\end{array}$} & \multirow{5}{*}{$\begin{array}{c}\text { TFR decrease } \\
\text { from } 1.8 \text { to } 1.6 \text { by } \\
2031 \text { and } \\
\text { constant } \\
\text { thereafter }\end{array}$} \\
\hline High migration & $+30,000$ per annum & & \\
\hline Low migration & $+5,000$ per annum & & \\
\hline CSO M3F2 & $+10,000$ per annum & & \\
\hline CSO M2F2 & $+20,000$ per annum & & \\
\hline Morgenroth (2018) & $+12,500$ per annum & Based on 2011 LT & Constant 1.8 TFR \\
\hline
\end{tabular}

Sources: CSO (2018), Morgenroth (2018) and authors' calculations.

Given the uncertainty inherent in any projection exercise, particularly regarding the likely future path of international migration, we examine a number of alternative scenarios. Figure 4.1 also includes the national population projections for the high and low international migration scenarios. As the Figure shows, the headline results are highly sensitive to international migration flows. In the high international migration scenario which assumes a sustained net inflow of 30,000 international migrants per year, the total population in Ireland would reach almost six million people by 2040, implying an annual average growth rate of around 1.0 per cent. Conversely, the low international migration scenario projects 5.554 million people by 2040 . The differences with respect to the baseline scenario, by the end of the projection horizon are significant, amounting to $+318,000$ people in the high international migration scenario and -112,000 in the low international migration scenario. This highlights the point raised earlier that 
the evolution of international migration flows is a key determining element of the future population, and changes in the projected level of these flows leads to significant changes in the projections. However, as mentioned earlier, it is difficult to predict these flows as they are incredibly volatile and depend not only on domestic economic conditions but on international economic conditions. As such, it is prudent to consider a range of international migration scenarios, given that a change in economic conditions or migration patterns could severely alter the projected path of the population.

\subsection{POPULATION PROJECTIONS - REGIONAL}

Table 4.2 shows the regional distribution of the Baseline projections in 2040 together with the results in Morgenroth (2018). Appendix Table B.2 shows the Baseline projections at a county level, at various intervals, together with the implied county-level population growth over the projection horizon in the Baseline, high and low international migration scenarios. The Eastern and Midland region, which had the highest population share in 2016, is the NUTS 2 region expected to experience the fastest growth, increasing its share of the total population to 50 per cent by 2040. The Eastern and Midland region is projected to capture the majority (55.6 per cent or 514,000 people) of the total expected population growth over the 2016 to 2040 period. Within the region, Dublin is expected to continue to be the NUTS 3 region with the highest population share, although the Mid-East region, the area surrounding Dublin, registers the fastest population growth. Furthermore, in contrast with the results in Morgenroth (2018), the Midlands region shows higher than average growth, due to the dynamism of Carlow and Laois. Population growth is also expected to be higher than average in the NUTS 2 Southern region, with particularly growth across the South coast. Finally, the projection results suggest that the slowest growing region will continue to be Northern and Western region, showing signs of an ageing population, with county Mayo as the slowest growing county. Overall, differences in population growth at a county level over the projection horizon to 2040 display less variability compared to the previous 1996 to 2016 period (see Appendix Tables B.1 and B.2). 
TABLE 4.2 POPULATION PROJECTIONS, ANNUAL GROWTH RATES AND POPULATION SHARES, 2016-2040

\begin{tabular}{|c|c|c|c|c|c|c|c|c|}
\hline & \multicolumn{3}{|c|}{ Population ('000) } & \multicolumn{2}{|c|}{$\begin{array}{c}\text { Annual Growth, } \\
2016-2040\end{array}$} & \multicolumn{3}{|c|}{ Population share (\% of total) } \\
\hline & 2016 & $\begin{array}{c}2040 \\
\text { Baseline }\end{array}$ & $\begin{array}{l}2040 \\
\text { M18 }\end{array}$ & $\begin{array}{c}\text { Baseline } \\
\%\end{array}$ & $\begin{array}{c}\text { M18 } \\
\%\end{array}$ & $\begin{array}{c}2016 \\
\%\end{array}$ & $\begin{array}{c}2040 \\
\text { Baseline } \\
\%\end{array}$ & $\begin{array}{c}2040 \\
M 18 \\
\%\end{array}$ \\
\hline State & $4,739.6$ & $5,665.5$ & $5,634.8$ & 0.7 & 0.7 & 100.0 & 100.0 & 100.0 \\
\hline Eastern and Midland & $2,318.2$ & $2,832.9$ & $2,839.2$ & 0.8 & 0.8 & 48.9 & 50.0 & 50.4 \\
\hline Dublin & $1,341.4$ & $1,608.2$ & $1,639.8$ & 0.8 & 0.8 & 28.3 & 28.4 & 29.1 \\
\hline Mid-East & 685.8 & 861.0 & 868.9 & 1.0 & 1.0 & 14.5 & 15.2 & 15.4 \\
\hline Midlands & 291.0 & 363.6 & 330.5 & 0.9 & 0.5 & 6.1 & 6.4 & 5.9 \\
\hline Northern and Western & 843.7 & 962.1 & 961.6 & 0.5 & 0.5 & 17.8 & 17.0 & 17.1 \\
\hline Border & 392.6 & 457.0 & 427.6 & 0.6 & 0.3 & 8.3 & 8.1 & 7.6 \\
\hline West & 451.1 & 505.0 & 534.1 & 0.5 & 0.7 & 9.5 & 8.9 & 9.5 \\
\hline Southern & $1,577.6$ & $1,870.6$ & $1,833.9$ & 0.7 & 0.6 & 33.3 & 33.0 & 32.5 \\
\hline Mid-West & 471.2 & 541.9 & 550.0 & 0.6 & 0.6 & 9.9 & 9.6 & 9.8 \\
\hline South-East & 418.9 & 504.1 & 484.8 & 0.8 & 0.6 & 8.8 & 8.9 & 8.6 \\
\hline South-West & 687.5 & 824.6 & 799.2 & 0.8 & 0.6 & 14.5 & 14.6 & 14.2 \\
\hline
\end{tabular}

Source: Authors' calculations.

As our demographic model produces projections by single year of age, we can also examine the projected age composition of the population at a granular level. Figure 4.2 shows population age pyramids that illustrate the ageing of the population over the projection horizon. The first pyramid shows the numbers at each year of age by gender in the national population in 2016 and 2040. The figure allows us to see the ageing of the population, with the two peaks in the 2016 population at around ages five and 35 years shifting up the pyramid by 2040 . By 2040 , the numbers in the older age groups (in the higher part of the pyramid) are much higher and given the relatively flat projection for fertility, the overall pyramid is more top-heavy.

There are also differences in the population age structure at a county level. Figure 4.2 also shows the population pyramids for the youngest (Kildare) and the oldest (Mayo) counties. To ensure comparability (as the counties have different population sizes), the pyramids are presented as percentages of total county population for each year of age. Despite having a similar overall profile there are clear differences, with county Mayo having an older and more rapidly ageing population. In 2040, the share of population over the age of 65 is projected to be 53 per cent in Mayo compared to just 38 per cent in Kildare. The demographic projections highlight both the ageing of the population in the near future and the regional differences in this process, which will have implications for many areas including the type of housing demand in the future. 
FIGURE 4.2 POPULATION AGE PYRAMIDS: NATIONAL 2016-2040 (POPULATION, TOP); KILDARE AND MAYO 2040 (\% OF TOTAL COUNTY POPULATION, BOTTOM)
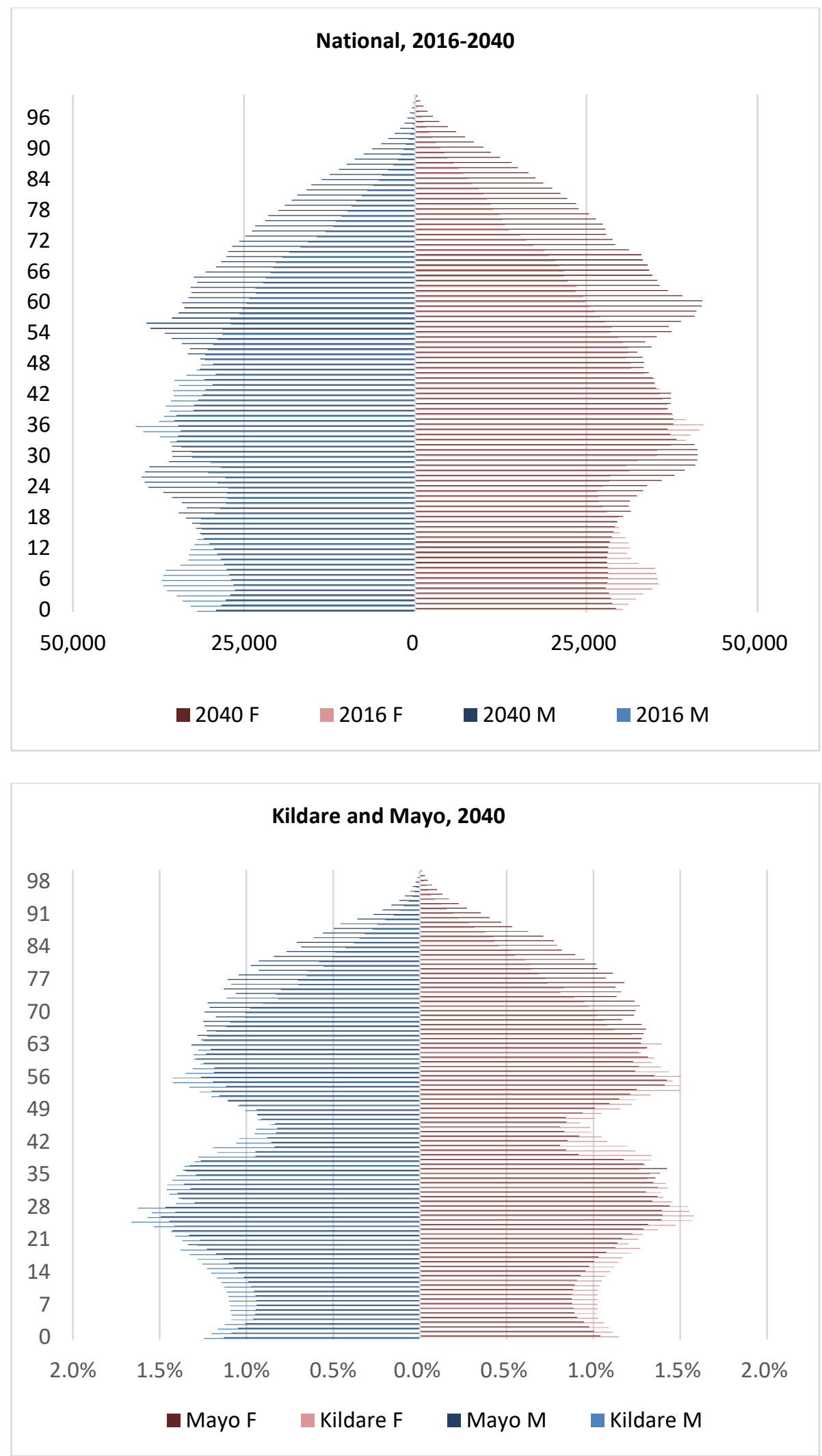

Source: Authors' calculations. 

MORGENROTH (2018)

One of the advantages of modelling internal migration as a function of county-level economic conditions is that we can create alternative scenarios by altering these conditions. In this section, we generate a scenario based on the national projections from the baseline scenario that matches the county-level population distribution of the 50:50 City scenario contained in Morgenroth (2018). We explore how the attractiveness of certain counties would have to change in order to alter the internal population flows enough to shift the population distribution at county level from that projected in the baseline scenario to that described in the 50:50 City scenario. The 50:50 City scenario is built on two assumptions. Firstly, that 50 per cent of the population growth between 2016 and 2040 occurs in the Eastern and Midland region; our baseline projects a figure of 55.6 per cent (and the original 'current trends' scenario in Morgenroth (2018) projected a figure of 58.5 per cent). Secondly, that the additional population growth will be focused on the major cities within each region, with the increases for each county roughly proportional to the size of their largest urban centre. The scenario captures two potential policy objectives: aiming to have population growth more evenly distributed and less centred around Dublin and its surrounding area, and also taking advantage of the potential efficiency gains from large agglomerations which imply more concentration. These policy objectives are represented in the National Planning Framework 2040 as National Policy Objectives 1a and 2a.

Comparing the 50:50 City scenario with the baseline projection here reveals the main differences are in the counties of Galway, Cork and Limerick. Whereas in the 50:50 City scenario these counties capture 6.3 per cent, 12.4 per cent and 4.9 per cent, respectively, of the total population in 2040, in the baseline these figures are 5.2 per cent, 11.5 per cent and 4.0 per cent respectively. In the current version of our demographic model, we have three levers that can be used to increase the attractiveness of a county: lower unemployment (more employment opportunities), lower house prices and higher disposable income. Changing the relative attractiveness of counties would induce changes in internal migration flows, which would shift the county population distribution generated by the baseline projection to another desired distribution. There are multiple combinations of changes in these variables that could increase relative county attractiveness enough to achieve this; here we focus on altering county disposable incomes, leaving unemployment rates and house prices unchanged. An important caveat is that recent research (Kostarakos et al., forthcoming) has shown that there is a positive elasticity between disposable income and house prices, whereby within many counties increases in disposable income would induce even higher increases in house prices. Therefore, the assumption of increases in disposable incomes while house prices remain unchanged would imply the introduction of measures to mitigate the increase of house prices to absorb the effect of higher incomes. 
To generate a regional distribution of population comparable to that of 50:50 City, we make two changes to the assumptions contained in the baseline scenario. Firstly, the annual growth rate of disposable income in Limerick, Cork, Galway and Waterford is increased by 1.5pp, 1.3pp, 1.0pp and 1.0pp, respectively. The increase in disposable income makes these counties which host the main cities relatively more attractive, allowing them to capture a higher share of internal population movements. Secondly, the increase in disposable incomes in certain counties makes them more attractive to international migration and these counties increase their share of international migration flows. Increasing one county's share implies lowering the share of other counties; the changes have been made with a view to maintaining the projected shares within the range of their historical values.

The results of this exercise are shown in Figure 4.3. The figure on the left shows the internal migration pattern in $\mathbf{2 0 4 0}$ generated by the baseline assumptions, in a map similar to Figure 2.6 in Section 2 but in this case with the arrows representing net flows larger than 400 people a year. The pattern generated is very similar to that of 2016, which represented a softer version of the Dublin Outflow model. There is an average net outflow from Dublin of a little over 6,000 people per annum, going mostly to the counties around Dublin, and with most of the rest of the country picking up small net gains of internal migrants. The figure on the right shows the internal migration pattern generated by changing economic conditions in such a way as to achieve a population distribution comparable to the 50:50 City scenario. The main difference between the two scenarios is how the target counties increase their annual net inflow of internal migrants, even receiving some large flows from Dublin. Additionally, the improved attractiveness of these counties increases the flows from surrounding counties, resulting in counties like Clare and Mayo losing in terms of net internal migration. 
FIGURE 4.3 INTERNAL MIGRATION IN 2040 UNDER THE BASELINE AND THE 50:50 CITY SCENARIOS

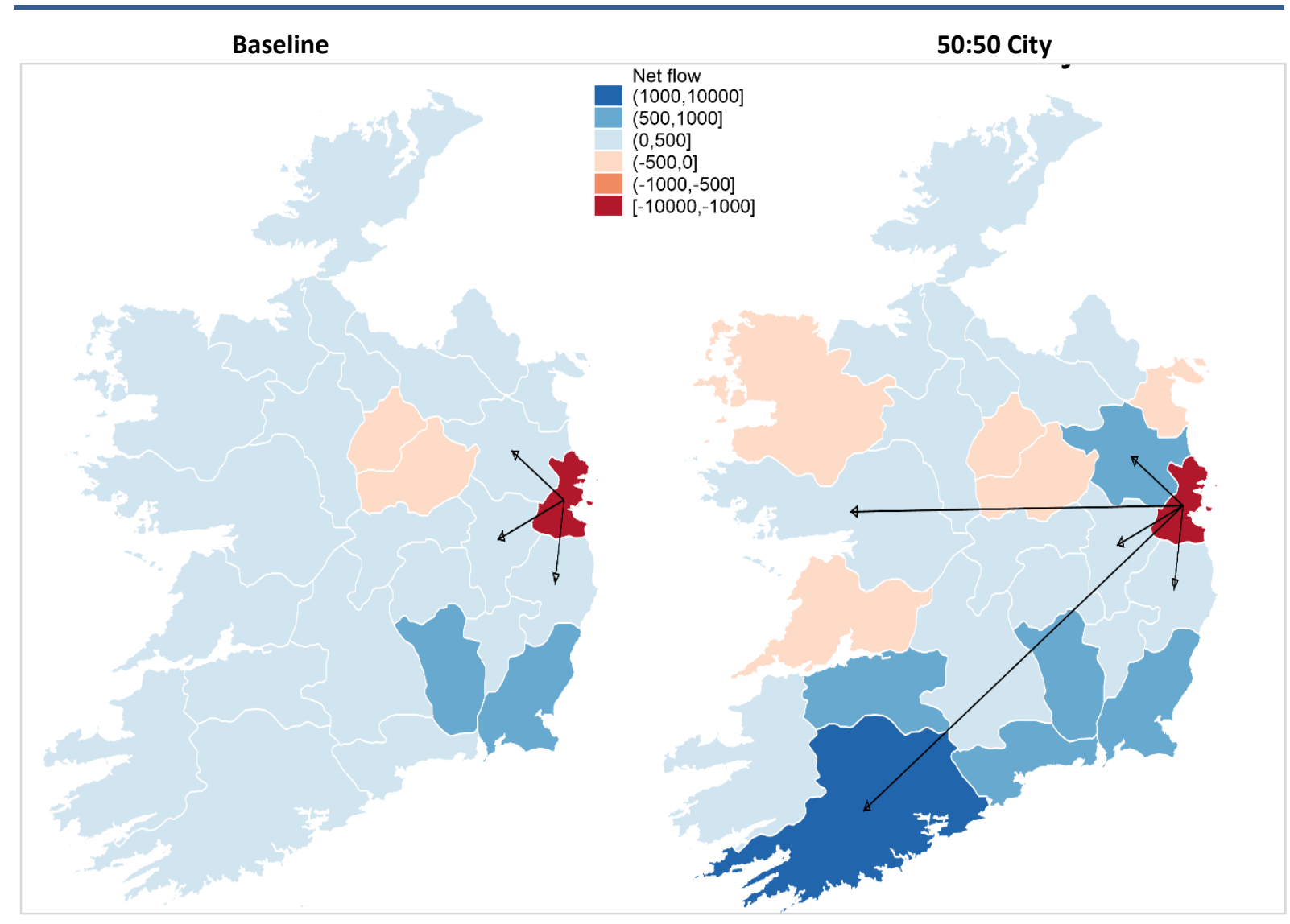

Source: Authors' calculations. 


\section{CHAPTER 5}

\section{Housing demand projections}

\section{$5.1 \quad$ INTRODUCTION}

This section converts the population projection scenarios into estimates of the structural demand for housing i.e. the amount of housing warranted by the evolution of the population over the projection horizon consistent with the state of broad underlying economic conditions. To achieve this, estimates of the tendency for people to form an independent household (household formation) are needed. Census data on headship rates ${ }^{21}$ are used to calculate new household formation. It should be noted that housing demand is expected to be larger than new household formation in the short term to deal with the deficit that has built up since 2010.

Using the county-level regional demographic model, we examine housing demand at a more granular level (at a local authority level). ${ }^{22}$ To move from county level to local authority level, assumptions are needed on how the county population, by five-year age groups, is allocated between different local authorities within some counties. We apply the shares of population by five-year age groups at local authority level from the 2016 Census and assume the shares remain constant over the projection horizon. ${ }^{23}$ Finally, the analysis in this section deals with future housing demand based on demographic projections and therefore does not take into account any potential pent-up demand remaining in the Local Authorities.

\subsection{HEADSHIP RATES}

Table 5.1 shows headship rates by five-year age groups from the Census years between 1996 and 2016. They are calculated as the number of private households in permanent housing units divided by population, per local authority and five-year age group. In terms of the age structure, the table shows a steep increase in headship rates up to age 35 and a more gradual increase beyond that age. The Table also shows there has been some movement in headship rates in recent years. During the Celtic Tiger years and up to the Great Recession, headship rates had

21 Headship rates are the proportion within each age group who identify themselves as the head of an independent household.

22 Following the Cork Local Government Review, the boundaries of Cork City and Cork County were changed in 2019. The new boundaries increased the area and population of Cork City at the expense of Cork County, with the population within the new city bounds increasing from 125,000 to 215,000. This report uses 2016 Census data to disaggregate the county results into local authorities and therefore all results presented from this point reflect the old boundary definition for Cork.

23 For example, if 15.1 per cent of the population aged between 25 and 29 years old in county Dublin live in Fingal County Council in 2016, we assume that Fingal captures 15.1 per cent of the population of county Dublin of this age group throughout the projection period. 
been steadily increasing in Ireland at a national level, with the biggest increases seen for the younger age groups. In particular, between 1996 and 2002 there were large increases in headship rates for those aged 20-29, between 2002 and 2006 the biggest increases were recorded for those aged 25 to 34, while between 2006 and 2011 the biggest increases were for those aged 30 to 44 . In the aftermath of the Great Recession, overall headship rates fell between 2011 and 2016, with almost all age groups showing a decline over the period with the largest falls recorded for the younger age groups. Table 5.1 also includes information for 2016 of the maximum and minimum headship rates at local authority level. These numbers reveal significant regional differences in headship rates.

For our baseline projection, we assume that the five-year age group headship rates are constant at their 2016 levels throughout the projection horizon. This means we calculate the number of households in a local authority as the sum over all fiveyear age groups of the product of the population by five-year age group and the appropriate headship rate. After calculating the number of households on a yearly basis, we simply define household formation (the number of new households) as the difference in the number of households from one year to the next. By keeping headship rates at their 2016 levels, our projections take differences between age groups and regions into account. Household formation scenarios with richer headship rates assumptions are an avenue for future work. ${ }^{24}$

TABLE 5.1 HEADSHIP RATES BY FIVE-YEAR AGE GROUP, 1996-2016; 2016 MAX AND MIN

\begin{tabular}{|l|l|l|l|l|l|l|l|}
\hline & $\mathbf{1 9 9 6}$ & $\mathbf{2 0 0 2}$ & $\mathbf{2 0 0 6}$ & $\mathbf{2 0 1 1}$ & $\mathbf{2 0 1 6}$ & \multicolumn{1}{|c|}{$\mathbf{2 0 1 6 \text { Min }}$} & \multicolumn{1}{|c|}{$\mathbf{2 0 1 6}$ Max } \\
\hline All ages & $\mathbf{3 1 . 0}$ & $\mathbf{3 2 . 9}$ & $\mathbf{3 4 . 7}$ & $\mathbf{3 6 . 1}$ & $\mathbf{3 5 . 7}$ & $\mathbf{3 2 . 6}$ (Fingal) & $\mathbf{3 9 . 3}$ (Cork City) \\
\hline $20-24$ & 14.9 & 18.9 & 19.3 & 18.7 & 14.2 & 6.6 (Meath) & 30.4 (Galway City) \\
\hline $25-29$ & 29.3 & 31.2 & 33.8 & 35.4 & 29.6 & 24.2 (Wicklow) & 35.0 (Galway City) \\
\hline $30-34$ & 42.4 & 42.9 & 45.0 & 46.9 & 43.3 & 40.8 (Wicklow) & 46.7 (Waterford) \\
\hline $35-39$ & 48.2 & 47.8 & 49.2 & 51.0 & 49.5 & 47.8 (Kerry) & 51.8 (Waterford) \\
\hline $40-44$ & 51.0 & 50.8 & 51.3 & 53.1 & 52.7 & 51.1 (Wicklow) & 54.3 (Galway City) \\
\hline $45-49$ & 52.5 & 52.4 & 53.5 & 54.3 & 54.5 & 52.5 (DL-Rathdown) & 57.1 (Leitrim) \\
\hline $50-54$ & 54.5 & 53.4 & 55.1 & 56.2 & 55.7 & 54.2 (Kilkenny) & 57.7 (Leitrim) \\
\hline $55-59$ & 56.2 & 55.2 & 56.1 & 57.2 & 57.0 & 55.0 (Galway City) & 58.7 (Tipperary) \\
\hline $60-64$ & 59.1 & 56.9 & 57.6 & 58.1 & 58.0 & 55.2 (Galway City) & 61.4 (Leitrim) \\
\hline 65 and over & 62.6 & 61.9 & 62.6 & 63.0 & 62.0 & 56.8 (Galway City) & 65.7 (Leitrim) \\
\hline
\end{tabular}

Source: CSO, Census, various issues.

24 For example, UK headship rates are consistently 4-6 percentage points higher than in Ireland for almost all age groups and 8-9 percentage points higher for the 25-34 age group. An exercise in which headship rates converge to current UK levels by 2050 shows that structural housing demand would increase by more than 7,000 dwellings a year on average over the 2019-2040 period. The increase to demand would be an additional 10,500 dwellings a year if the convergence were to happen by 2040. 


\subsection{OBSOLESCENCE}

In addition to structural housing demand generated by increases in the population we also incorporate an estimate of housing obsolescence. Every year, a number of dwellings become obsolete and need to be replaced. These obsolete dwellings serve to increase the amount of housing needed to meet demand. Therefore, we add an estimate of housing obsolescence to the increase in the number of households to obtain a final complete estimate of structural housing demand.

To estimate housing obsolescence, we follow the methodology in FitzGerald (2005). For the intercensal period, 2011-2016 in this case, the number of dwellings that became obsolete each year can be obtained by taking the change in the stock of dwellings between Censuses and subtracting this figure from the numbers of dwellings built over the relevant period. Comparing the 2011 to the 2016 Census shows an increase of 8,800 permanent housing units. At the same time, completions in the intercensal period, between the second quarter of 2011 and the first quarter of 2016, amounted to 29,319 dwellings. The difference between these two figures provides an estimate of obsolete dwellings: a total of 20,519 or 4,104 per annum. This results in an obsolescence rate (obsolete dwellings compared to the total housing stock) of 0.20 per cent.

Data availability, of both the housing stock from the Census and house completions, allows us to replicate this exercise at the local authority level. The results are shown in Figure 5.1. The smallest obsolescence rates for the 2011-2016 period are registered around Dublin and the South coast, whereas the largest are located on the North-West. For this analysis, we hold the regional obsolescence rates fixed at their 2016 levels for the duration of the projection period and we apply the same rates in all scenarios, ensuring our structural demand estimates take account of obsolescence. 


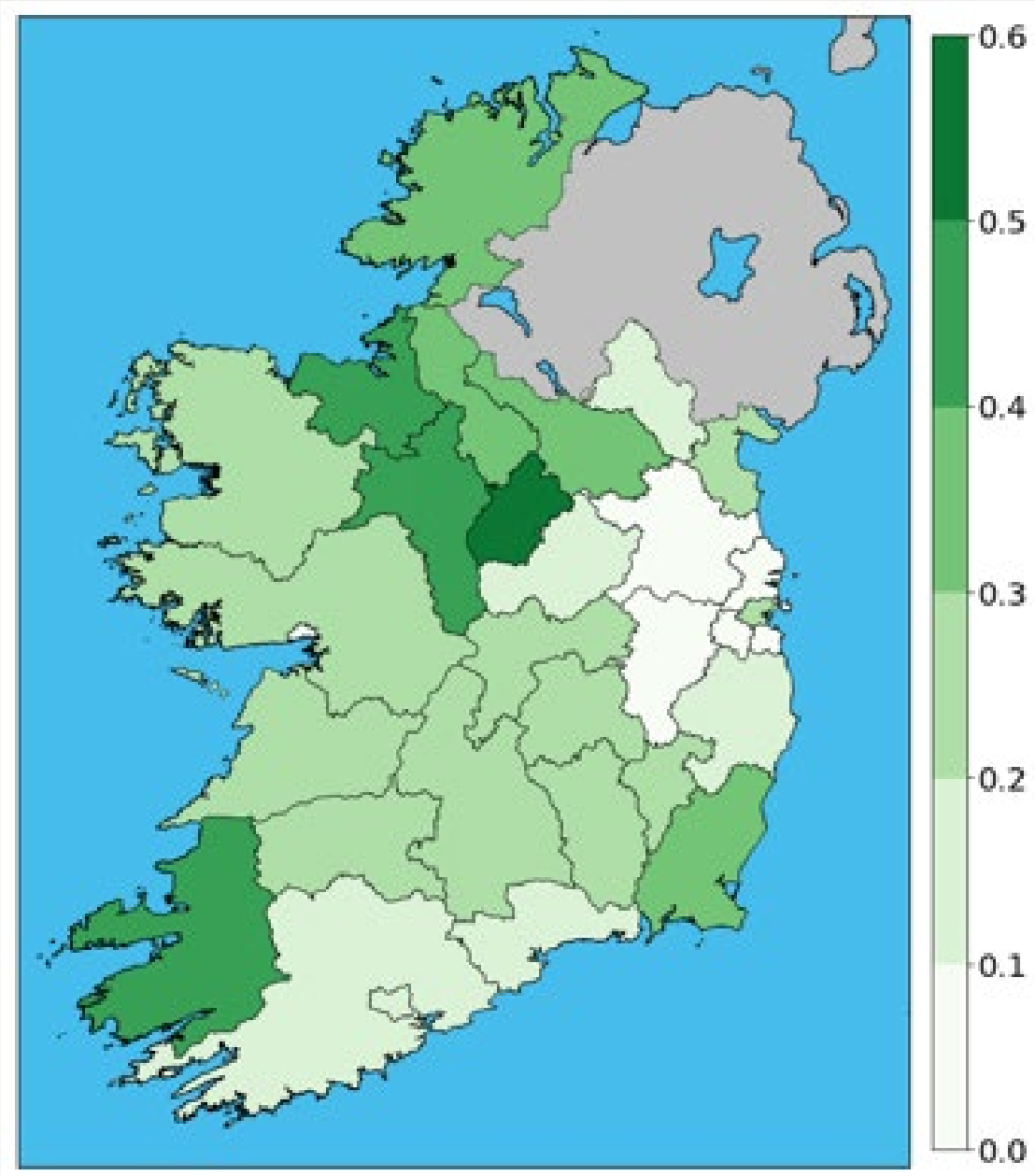

Source: Authors' calculations.

\subsection{HOUSING DEMAND AT A REGIONAL LEVEL}

The resulting household formation projections/housing demand at national level for all the scenarios, resulting from the aggregation of the projections at local authority level, is shown in Figure 5.2. ${ }^{25}$ The difference between the scenarios is driven by differences in international migration assumptions with higher net inflows of migrants naturally leading to higher levels of housing demand. Housing demand in the high international migration scenario is close to 33,000 per annum. This figure is close to the latest projections from the Central Bank (Conefrey and Staunton, 2019) of 34,000 dwellings a year up to 2030, which uses a similar assumption for international migration but assumes a slightly higher obsolescence rate. The baseline projection for housing demand is close to the high international migration scenario in the short-term and settles at around 28,000 new households per annum over the medium term as it moves towards its medium-term assumption of $+15,000$ net international migration per annum. In the baseline scenario, average housing demand for the $2018-2040$ period is 28,111 per annum, 
close to but above the 'at least 25,000 new homes' reported in the National Planning Framework (Department of Housing, Local Government and Heritage, 2018). Finally, all scenarios show signs of declining household formation towards the end of the projection, as the population ages. Our projections for the population and number of households indicate that the average number of people per household will decline from 2.81 persons per household in 2016 to 2.43 in 2040 .

FIGURE 5.2 STRUCTURAL HOUSING DEMAND: BASELINE, HIGH AND LOW MIGRATION SCENARIOS, 2017-2040

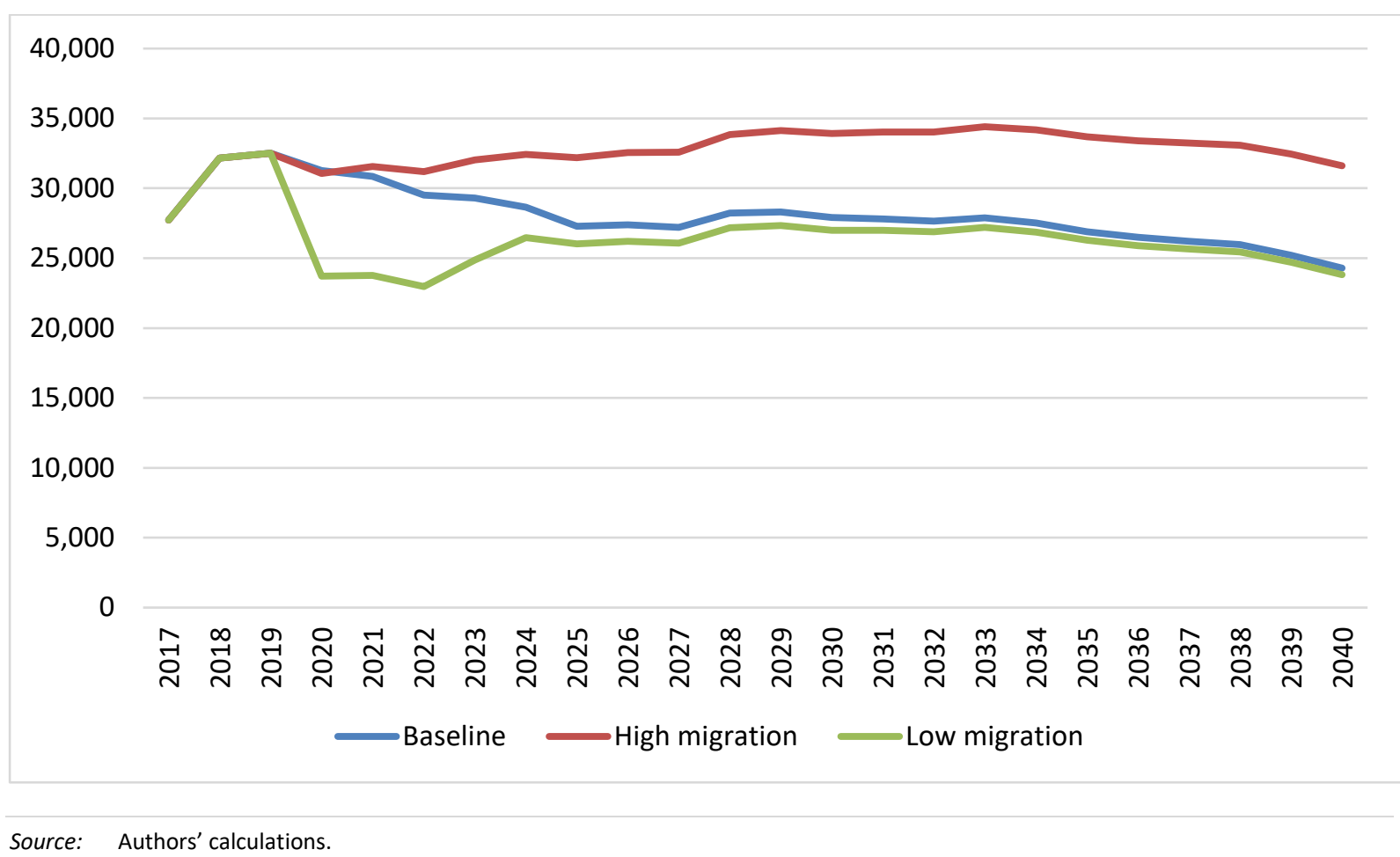

In terms of the geographical distribution of structural housing demand, naturally, local authorities with larger populations will have larger increases in housing demand and the age composition of the population will also play a role in determining housing demand. We have created a simple index to show which local authorities will have relatively higher housing demand. For each local authority, we calculate the difference between its housing demand as a share of the national total and its population share out of the total population. The index shows a positive value when local authorities are increasing the number of households faster than what would be implied by their population share and vice versa. ${ }^{26}$

26 For example, in 2030 Meath is projected to have a population slightly over 228,000 people, representing 4.3 per cent of the national total. At the same time, in 2030 Meath is projected to add 1,371 new households which is 4.9 per cent of the 27,902 new household formation expected at a national level. Therefore, the value of the index for Meath for 2030 is $0.6(=4.9-4.3)$, indicating that Meath is adding new households faster that we would expect given its population. 
The results for this index are shown in Figure 5.3, showing a comparison of the index for the baseline scenario with the 50:50 City scenario for the year 2030. The baseline scenario shows the higher levels of housing demand relative to its population share in Dún Laoghaire-Rathdown, Cork City, Meath and Laois, whereas the lowest levels are in Mayo, Cork County and especially Fingal. The 50:50 City scenario shows a different situation. More internal migration and a different distribution of international migration increase household formation with particular intensity in Limerick, but also in Cork County and Galway County, as well as to some degree in Galway City and Waterford.
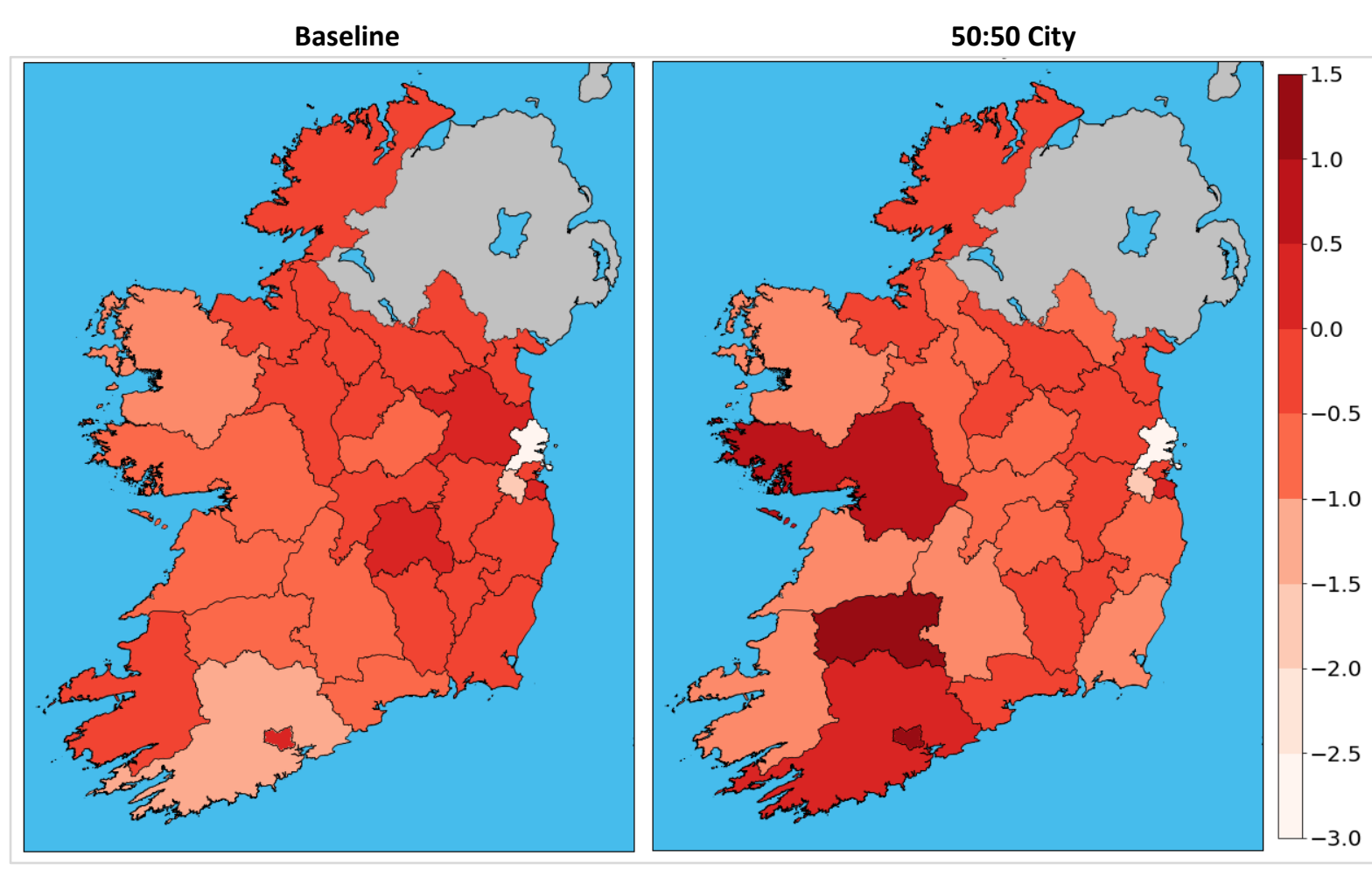

Source: Authors' calculations.

\subsection{TYPES OF HOUSING DEMAND - A QUALITATIVE ASSESSMENT}

Over the projection horizon, there may also be changes in the demand for different types of housing units. Existing data show differences by household age ${ }^{27}$ in terms of the types of housing units that are occupied. Therefore, as the population ages over the projection horizon, the change in the age structure will likely lead to changes in demand in the mix of housing units. Furthermore, the data also reveal there are differences in the incidence of different types of housing units across local authorities, with larger cities tending to have lower proportions of households in detached houses, irrespective of the age of the household, so differences in population growth across local authorities will also lead to changes in the demand 
mix of housing units. It is difficult to untangle these types of effects and it is also likely that over time changes in other factors such as preferences, income levels, the income distribution etc. will impact the demand for different types of housing. ${ }^{28}$ Here we provide an initial qualitative assessment of how some of these factors, namely population ageing and differences in population growth may influence changes in the demand for different types of housing units.

Figure 5.4 shows the different types of accommodation that households occupy at a national level in 2016 and also separately by age group of the household reference person. At a national level, the Figure shows that around 87 per cent of households live in detached, semi-detached or terraced houses, while around 12 per cent live in flats and apartments. However, this aggregate picture masks striking differences by age of the household reference person. For households where the reference person is over 65 years of age, the figure reveals that the overwhelming majority (94 per cent) live in detached, semi-detached or terraced houses while only 5 per cent live in flats and apartments; whereas in households where the reference person is under the age of 30, less than 60 per cent live in detached, semi-detached or terraced houses and 38 per cent live in flats and apartments. This relationship between age and type of housing unit generally prevails across all counties and cities. ${ }^{29}$

28 Changes in these factors will also contribute to changes in the nature of occupancy over time but an examination of this is beyond the scope of this report.

29 The future evolution of the relationship between age and type of housing unit in Ireland is an interesting avenue for future research, as the international evidence is mixed. For example, in Sweden, Abramsson and Andersson (2016) find that starting at 75 years old, respondents show a gradual change of preferences from large to small housing, from owner-occupation to rented housing. In Spain, however, Costa-Font et al. (2009) found a strong preference for 'ageing in place'. 
$60 \%$

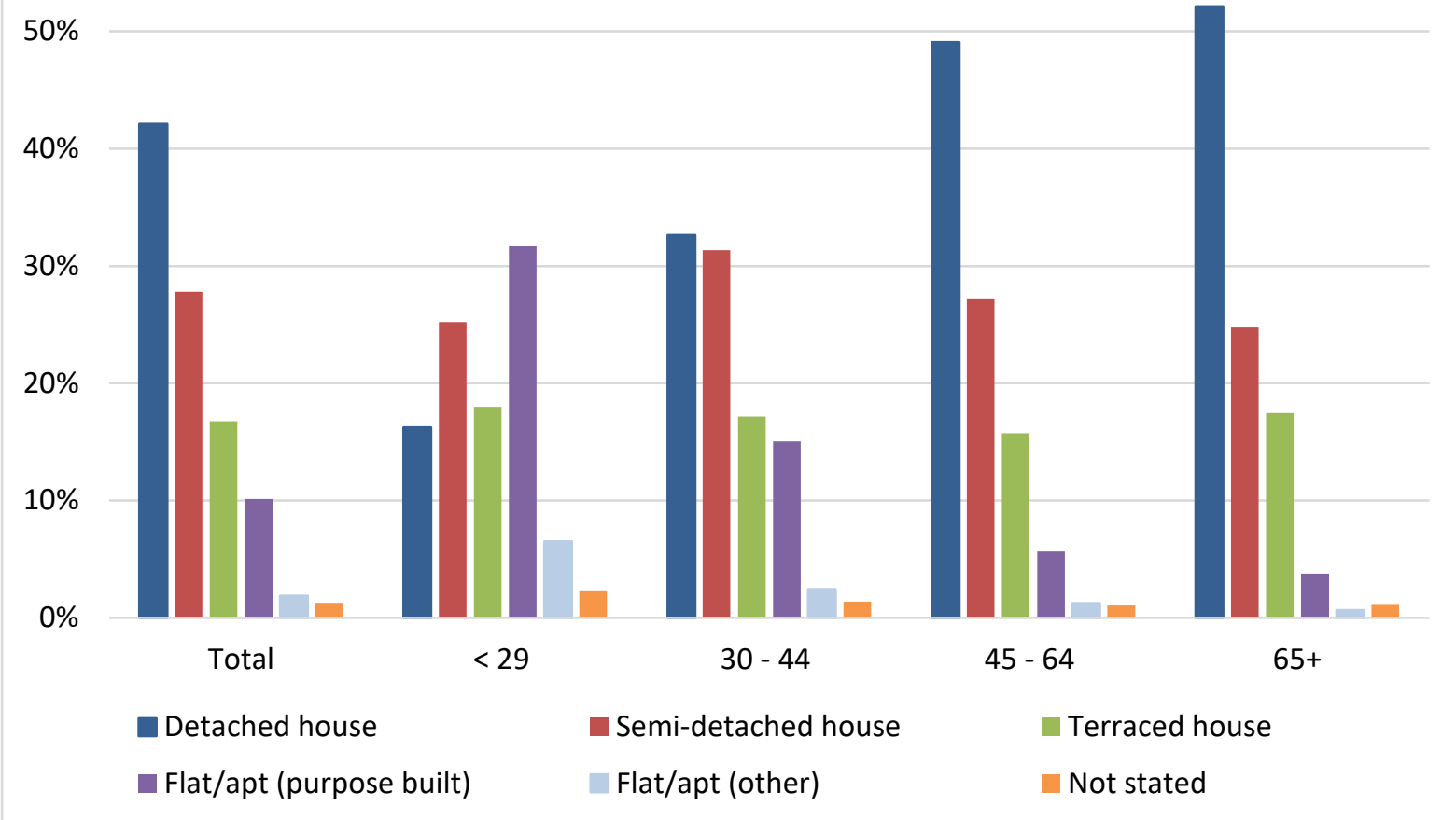

Source: Authors' calculations, based on a special tabulation from the 2016 Census.

There are also differences across local authorities with respect to the mix of different types of housing units. To illustrate this, Figure 5.5 displays the proportion of households by different types of types of housing units (for all ages and by age of household reference person) for Dublin City and Galway County in 2016. The Figure reveals that around 77 per cent of all households in Galway County live in detached houses compared to just 5 per cent in Dublin City, while 35 per cent of households in Dublin City live in flats and apartments, compared to just 4 per cent in Galway County. These types of patterns are evident across the age distribution of the household reference person, indicating that the differences are not simply driven by differences in the age profile between Dublin City and Galway County. 


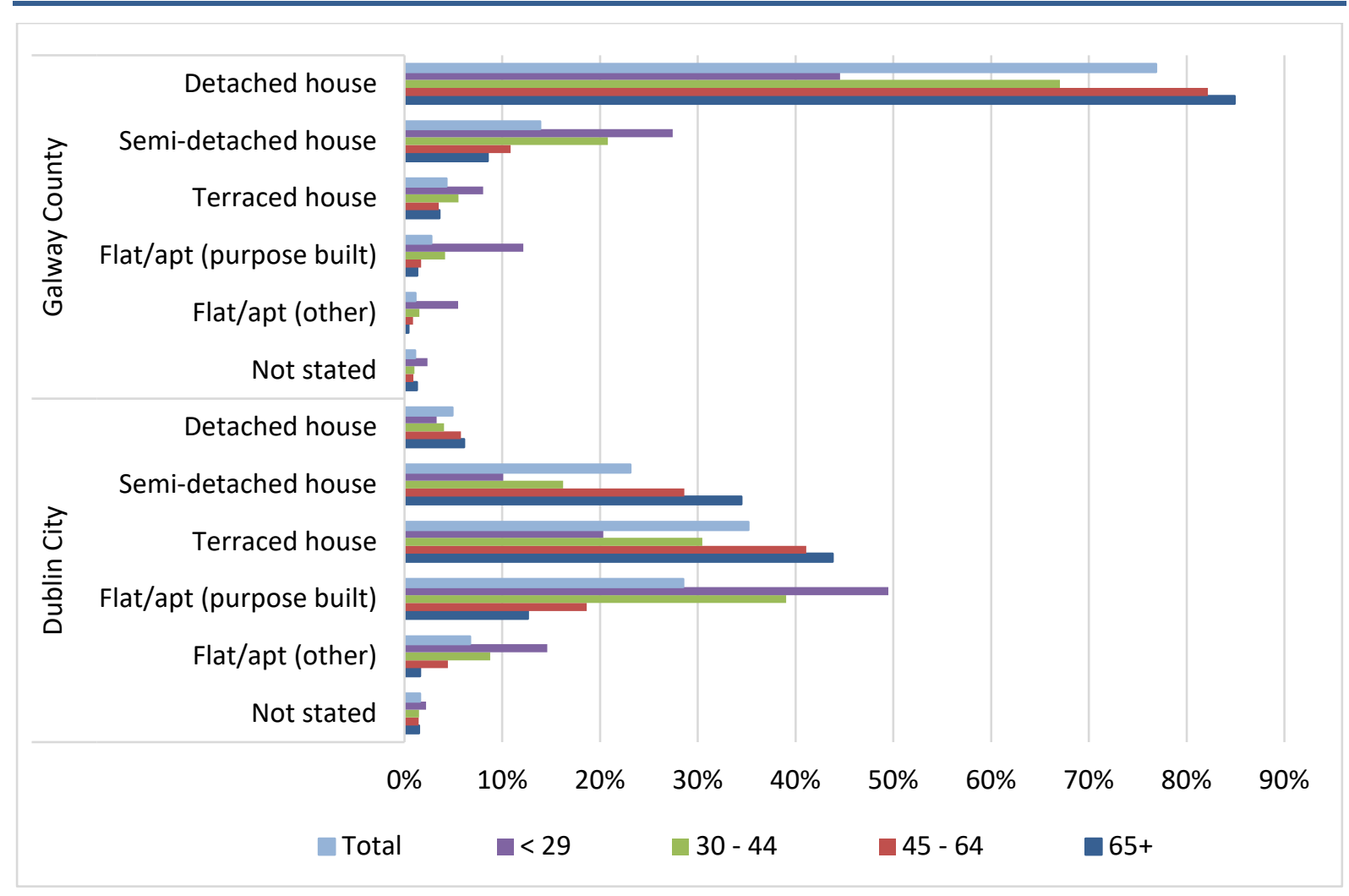

Authors' calculations, based on a special tabulation from the 2016 Census.

Combining the projected path of the population for each local authority with the observed differences in the mix of housing types, it could be possible to create an approximation to how the demand for different housing types could evolve up to 2040. Actual demand will depend on the evolution of factors including headship rates, income distribution and preferences at the local authority level. The analysis would reflect the ageing of the population that occurs in general, but it would also take into account how some local authorities will be affected more by this ageing process, as well as current differences in preferences for some types of housing at the regional level.

\subsection{IMPLICATIONS OF COVID-19 PANDEMIC ON PROJECTIONS}

This report focusses on generating estimates of structural housing demand at a regional level over the long term; it does not explicitly incorporate the potential effects of the COVID-19 pandemic on the population projections and estimates of housing demand. This section outlines the potential impacts of COVID-19 and discusses how, as a result of the pandemic, the estimates of housing demand may be closer to those in the low international migration scenario at least in the near term. 
As discussed earlier in the report, international migration is the key driver of population change in Ireland; these migration flows are rather unstable and depend on domestic relative to international economic conditions. While the COVID-19 public health crisis has precipitated a massive global and domestic economic shock, it may not necessarily affect relative economic conditions between Ireland and the international economy. However, the global pandemic may result in economic factors being less important in influencing migration flows in the near term. It is likely that travel restrictions, uncertainty about the evolution of the pandemic and lower confidence may result in migration being lower than in the baseline scenario at least in the short term. The low international migration scenario assumes that international migration falls from $+33,700$ in 2019 to $+5,000$ by 2022 and thereafter follows the Baseline scenario. This low international migration scenario is consistent with both/either a deterioration in relative economic conditions and/or migration being lower because of other external factors, such as the global health pandemic. The longer the pandemic and measures to contain it persist, the more likely estimates of structural housing demand will be closer to those in the low international migration scenario.

Furthermore, the sharp decline in economic activity, particularly in Q2 of this year will negatively affect the demand side of the housing market with lower incomes and higher unemployment affecting housing demand through the affordability channel (see Allen-Coghlan and McQuinn, 2020). The recovery in the residential market will depend on the recovery in the macro-economy and therefore it is likely that the housing demand estimates will be more consistent with the lower scenario in the short run.

In terms of any changes in internal migration, there are limited regional data available on the potential regional impact of COVID-19. Analysis by the Regional Assemblies of Ireland (2020) based on the regional distribution of the most exposed sectors to the economic disruption caused by COVID-19 suggests that the Northern and Western region may be the most impacted by COVID-19 with the Eastern and Midland region the least exposed. To the extent that COVID-19 has an uneven regional impact, especially in terms of employment opportunities and incomes, it may influence internal migration patterns. However, sufficient data and evidence are not currently available to assess the future direction of regional disparities. Lastly, if the current situation of increased remote working persists over time it could alter the decision of workers to move internally or commute, with a stronger preference for counties with lower house prices over those with robust labour markets when the jobs can be performed remotely. 


\section{CHAPTER 6}

\section{Conclusions}

This report provides estimates of structural housing demand at a local authority level out to 2040. These estimates are based on a new regional demographic model that explicitly incorporates the economic mechanisms that determine internal migration, and projections for headship rates. Given the dominant role that international migration plays in shaping the overall size, age structure and regional distribution of the population in Ireland, we examine a range of alternative scenarios for international migration. The assumptions underlying these scenarios draw heavily from recent trends and patterns in the data as well as findings on how certain key determinants of population change behave and react to the economic environment. Therefore, they implicitly assume that the types of relationships that were evident in the past will be maintained into the future. We also consider a scenario based on the 50:50 City Scenario from Morgenroth (2018) where population growth is more evenly distributed and less centred around Dublin and its surrounding area, and examine how relative regional economic conditions have to change to achieve these targets.

At a national level, in the baseline scenario, the population is expected to increase by around 926,000 people between 2016 and 2040 resulting in a total population of over 5.665 million people by the end of the period. This represents significant population growth (average of 0.7 per cent per annum), which has clear implications for planning in many areas including housing. These projections are highly sensitive to international migration flows and in a high international migration scenario the total population would reach almost six million people by 2040, whereas in a low international migration scenario the population would stand at around 5.554 million people by 2040 . The difference in population in 2040 compared to the baseline scenario $(+318,000$ people in the high international migration scenario and $-112,000$ in the low international migration scenario) provides a credible range for the future evolution of the population and also helps highlight the uncertainty in this type of exercise.

At a regional level, in the baseline scenario the Eastern and Midland region is expected to experience the fastest population growth and to capture the majority (55.6 per cent or 514,000 people) of the total expected population growth over the 2016 to 2040 period. Within this region, Dublin is expected to continue have the highest population share, although the Mid-East region, the area surrounding Dublin, is likely to experience the fastest population growth. The projection results also suggest that the slowest growing region will continue to be the Northern and Western region, showing signs of an ageing population. Overall, differences in 
population growth at a county level over the projection horizon to 2040 are more muted compared to the 1996 to 2016 period.

By applying county-level age-specific headship rates and incorporating expected housing obsolescence, we can convert the population projections into estimates of structural housing demand. In the baseline scenario, the level of housing demand is around 28,000 per annum over the medium term, although it is higher in the short-run given recent net international migration inflows. Housing demand in the high international migration scenario is close to 33,000 per annum and is around 26,000 per annum in the low international migration scenario. Our baseline scenario results suggest, relative to population shares, higher levels of housing demand in Dún Laoghaire-Rathdown, Cork City, Meath and Kildare and relatively lower levels of demand in Mayo and Fingal. A different regional pattern emerges in the 50:50 City scenario. More internal migration, and a different distribution of international migration, lead to higher increases in housing demand particularly in Limerick, but also in Cork County and Galway County, as well as to some degree in Galway City and Waterford. The higher increases in some local authorities come at the expense of lower increases in others such as Meath and Kildare, whereas some local authorities would see lower housing demand over time including Kerry, Tipperary and Wexford. 


\section{REFERENCES}

Abramsson, M. and E. Andersson (2016). 'Changing Preferences with Ageing Housing Choices and Housing Plans of Older People', Housing, Theory and Society, 33(2): 217-41

Allen-Coghlan, M. and K. McQuinn (2020). 'Property prices and COVID-19 related administrative closures: What are the implications?', ESRI Working Paper No. 661, May 2020, available at: https://www.esri.ie/system/files/publications/WP661_0.pdf

Barrett, A., J. FitzGerald and B. Nolan (2002). 'Earnings inequality, returns to education and immigration into Ireland', Labour Economics, 9(5): 665-80.

Beine, M. and C. Parsons (2015). 'Climatic Factors as Determinants of International Migration', The Scandinavian Journal of Economics, 117(2): 723-767.

Beine, M., S. Bertoli and J. Fernández-Huertas Moraga (2016). 'A Practitioners' Guide to Gravity Models of International Migration', The World Economy, 39(4): 496-512.

Bergin, A., A. García Rodríguez, N. Mclnerney and E. Morgenroth (2016). 'Baseline: Methodology, Assumptions and Projections', in Bergin, A., E. Morgenroth and K. McQuinn (eds.), Ireland's Economic Outlook: Perspectives and Policy Challenges, ESRI Forecasting Series EO1.

Bergin, A., N. Conroy, A. García Rodríguez, D. Holland, N. McInerney, E. Morgenroth et al. (2017). 'COSMO: A new COre Structural MOdel for Ireland'. ESRI Working Paper. No 553, ESRI.

Bertoli, S. and J. Fernández-Huertas Moraga (2015). 'The size of the cliff at the border', Regional Science and Urban Economics, 51: 1-6.

Conefrey, T. and D. Staunton (2019). 'Population Change and Housing Demand in Ireland', Central Bank of Ireland Economic Letters, Vol. 2019, No. 14.

Costa-Font, J., D. Elvira and O. Mascarilla-Miró (2009). 'Ageing in Place? Exploring Elderly People's Housing Preferences in Spain', Urban Studies 46(2): 295-316

CSO (2013). 'Population and Labour Force Projections: 2016-2046', Central Statistics Office.

CSO (2018). 'Population and Labour Force Projections: 2017-2051', Central Statistics Office.

CSO (2019a). 'Mortality Differentials in Ireland 2016-2017', Research Paper. Central Statistics Office.

CSO (2019b). 'Regional Population Projections 2017-2036'. Central Statistics Office.

CSO (2019c). 'Population and Migration Estimates'. Central Statistics Office.

Department of Housing, Planning and Local Government (2018)'. Project Ireland 2040: National Planning Framework'. 
FitzGerald, J. (2005). 'The Irish Housing Stock: Growth in Number of Vacant Dwellings', Quarterly Economic Commentary: Special Articles, Spring 2005.

Kostarakos, I., C. O’Toole and A. García Rodríguez (forthcoming). 'Testing the Determinants of County House Prices in Ireland', forthcoming research under the Research Programme in Housing Economics.

McQuinn, K., C. O'Toole and M. Allen-Coghlan (2019). Quarterly Economic Commentary, Autumn 2019, Dublin: ESRI.

Morgenroth, E. (2018). Prospects for Irish regions and counties: scenarios and implications, Research Series No. 70, Dublin: ESRI.

Ortega, F. and G. Peri (2013). 'The effect of income and immigration policies on international migration', Migration Studies, 1(1): 47-74, https://doi.org/10.1093/migration/mns004.

Pesaran, M.H. (2006). 'Estimation and Inference in Large Heterogenous Panels with a Multifactor Error Structure', Econometrica, 74(4): 967-1012.

Pesaran, M.H. (2015). 'Testing Weak Cross-Sectional Dependence in Large Panels', Econometric Reviews, 34:6-10, 1089-1117, DOI: $10.1080 / 07474938.2014 .956623$

Ramos, P. (2017). 'Modelling Migration', in L. Matyas (ed.), The Econometrics of Multi-dimensional Panels, Advanced Studies in Theoretical and Applied Econometrics 50, DOI 10.1007/978-3-319-60783-2_13.

Regional Assemblies of Ireland (2020). 'COVID-19 Regional Economic Analysis', available at: http://www.southernassembly.ie/uploads/generalfiles/CV19-Regional-Economic-Analysis.pdf

Whelan, S. (2008). 'Projecting Population Mortality for Ireland', Journal of the Statistical and Social Inquiry Society of Ireland, XXXVII, (2007/2008) pp. 135-163.NDIX 1.

Wren, M.A., C. Keegan, B. Walsh, A. Bergin, J. Eighan, A. Brick, S. Connolly, D. Watson and J. Banks (2017). Projections of demand for healthcare in Ireland, 2015-2030: First report from the Hippocrates Model, ESRI Research Series No. 67. 


\section{APPENDIX A}

\section{Internal migration methodology and data}

The theoretical framework adopted is the Random Utility Model. ${ }^{30}$ Our interest is in estimating the migration flows between counties, which can be expressed as $m_{j k t}=p_{j k t} s_{j t}$ where $m_{j k}$ is the flow from county $j$ to county $k$ at time $t, p_{j k t}$ is the proportion of residents out of the total stock $s_{j t}$ of population in county $j$ at time $t$ that decide to migrate to county $k$. The utility of an individual living in county k at time $t$ who resided in county $\mathrm{j}$ the previous period can be expressed as $U_{\mathrm{ijkt}}=\mathrm{w}_{\mathrm{jkt}}$ $\mathrm{c}_{\mathrm{jkt}}+\varepsilon_{\mathrm{ijkt}}$, where the utility $\mathrm{U}_{\mathrm{ijkt}}$ of the individual is a function of a deterministic component of utility $w_{j k t}$, the time specific cost of moving from one county to another $c_{\mathrm{jkt}}$, and an individual specific stochastic term $\varepsilon_{\mathrm{ijkt}}$. The deterministic component of utility and the cost of moving can be made a function of other observed variables, such as house prices, wages or distance. Following some basic assumptions about the statistical properties of the stochastic component of utility, we can operate and rearrange terms in a way that resembles a classic gravity equation:

$$
E\left(m_{j k t}\right)=\phi_{j k t} \frac{y_{k t}}{\Omega_{j t}} s_{j t}
$$

The expected gross flow between from county $j$ to county $k$ is a function of observable determinants of utility captured by $y$, observable determinants related to the cost of moving captured by $\phi$, the stock of population at the origin $s$ and the term $\Omega$, which captures the expected utility from all possibly destinations, including staying in the current county.

If we take the ratio relative to the number of stayers, normalise the cost of staying $\phi_{\mathrm{jj}}$ to one and take logs, the resulting equation is:

$$
\ln \left(\frac{E\left(m_{j k t}\right)}{E\left(m_{j j t}\right)}\right)=\ln \left(\phi_{j k t}\right)+\ln \left(y_{k t}\right)+\ln \left(y_{j t}\right)
$$

The terms for the stock of population s and the utility for alternative destinations $\Omega$ cancel out, so the log odds of migrating is a function of the cost of migrating and observable characteristics at origin and destination.

For the $\Omega$ term to cancel out, a strong assumption is necessary: independence of irrelevant alternatives. This assumption implies that the flows between two given 
counties depend only on the underlying conditions in those counties and are unaffected by changes in the attractiveness of any other third county. However, it is easy to imagine how this assumption could fail in the case of internal migration in Ireland. For example, consider the case of workers looking to move out of Dublin to one of the three counties contiguous to Dublin in order to commute to work. Keeping everything else constant, an increase of attractiveness in one of the contiguous counties, like a decrease in house prices, would have an effect on the flows between Dublin and the other two counties, even though nothing has changed in these other counties. Failing to control for these effects can lead to biased and inconsistent estimators.

Several solutions to this problem exist in the literature. The most comprehensive solution involves the use of the common correlated effects estimator proposed by Pesaran (2006); unfortunately, the time dimension of our panel is too short to consider its use. Alternatively, a set of fixed effects to control for the potential problem of cross-sectional dependence can be used, as in Beine and Parsons (2015) or Ortega and Peri (2013). We will follow Beine and Parsons (2015) and introduce origin and destination-time fixed effects, to control for time invariant origin factors and destination specific factors. Finally, to ensure that we have dealt with the possibility of strong cross-sectional dependence and, therefore, our estimation is consistent with our theoretical specification, we follow Bertoli and FernándezHuertas Moraga (2015) and use the CD test described by Pesaran (2015).

We estimate the following equation, adapted from Beine and Parsons (2015):

$$
\begin{aligned}
\ln \left(\frac{m_{j k t}}{\text { pop }_{j t}}\right)= & \frac{\ln \left(\text { expinc }_{k t}\right)}{\ln \left(\text { expinc }_{j t}\right)}+\ln \left(h p_{j t}\right)+\ln \left(\text { dist }_{j k}\right)+\operatorname{cont}_{j k}+\text { comm }_{j k}+D_{j} \\
& +D_{k t}+u_{j k t}
\end{aligned}
$$

The dependent variable is the log odds of migrating, i.e., the log of the share of the number of people who migrate out of the county from the total population. The explanatory variables are the ratio of expected incomes between destination and origin, house prices at origin, distance between counties, contiguity, dummies to control for commuting flows, and origin and destination-time dummies, as explained above. The ratio of expected incomes captures the decision process of the worker comparing the labour markets at origin and destination when deciding to migrate. Expected income is calculated as disposable income multiplied by 1 minus the unemployment rate and therefore a region becomes more attractive when either wages go up and/or unemployment goes down. Workers consider not only how high relative wages are, but how likely they are to get a job. Commuting dummies are dummies for the flows between Dublin and its three contiguous counties. Without these dummy variables, the model would predict a much larger migration flow between these counties due to relatively higher wages in Dublin, but in reality many workers choose simply to commute instead of moving to 
Dublin. These dummy variables help keep the predicted flow closer to its actual value and therefore capture the effect of commuting.

We estimate this equation using OLS. Whereas some studies in the literature use Poisson pseudo maximum likelihood (PPML) to estimate this type of equation, their motivation is that the large number of flows equal to zero in their data, up to 50 per cent in some cases, would introduce bias in their results. However, the amount of zero flows in our sample is just 0.5 per cent and therefore the use of OLS is justified. Furthermore, PPML tends to over-weight high flows (Ramos, 2017) which can be problematic in our case given the preponderance of Dublin, with close to 30 per cent of the total population.

\section{DATA}

Data on internal migration flows are obtained from the Census and, therefore, are not available yearly but with time gaps. The CSO provides information on the population resident in a given county that were living in a different county one year prior, allowing us to create a full matrix of gross migration flows between counties. Consequently, data availability forces the regional unit of analysis to be the county.

We examine possible determinants of internal migration including county house prices, labour market conditions and distance between counties. County house prices are taken from the CSO and are defined as the yearly median price for all dwelling statuses (new and existing), all buyer types and all sale types (market and non-market). County data start in 2010, therefore limiting our analysis to the 2011 and 2016 censuses, for a total of 1,300 observations. Labour market conditions are a combination of incomes and unemployment rates both at origin and destination, defined as the ratio between expected labour income at destination and expected labour income at origin. Expected labour income is calculated as the disposable income by person, taken from the County incomes and regional accounts, multiplied by 1 minus the unemployment rate, taken from the Census. Finally, distance is calculated in driving minutes between the main population centres of each given pair of counties. 



\section{APPENDIX B}

TABLE B.1 USUALLY RESIDENT POPULATION BY COUNTY

\begin{tabular}{|c|c|c|c|c|c|c|}
\hline & \multicolumn{5}{|c|}{ Population ('000) } & \multirow{2}{*}{$\begin{array}{c}\text { Annual Growth, } \\
\text { 1996-2016 } \\
\%\end{array}$} \\
\hline & 1996 & 2002 & 2006 & 2011 & 2016 & \\
\hline State & $3,626.1$ & $3,917.2$ & $4,232.9$ & $4,574.9$ & $4,739.6$ & 1.3 \\
\hline Carlow & 41.6 & 46.0 & 50.3 & 54.5 & 56.7 & 1.6 \\
\hline Cavan & 52.9 & 56.5 & 63.9 & 73.0 & 75.8 & 1.8 \\
\hline Clare & 94.0 & 103.3 & 110.8 & 116.9 & 118.3 & 1.2 \\
\hline Cork & 420.5 & 447.8 & 480.5 & 517.5 & 540.5 & 1.3 \\
\hline Donegal & 130.0 & 137.6 & 147.0 & 160.7 & 158.5 & 1.0 \\
\hline Dublin & $1,058.3$ & $1,122.8$ & $1,185.2$ & $1,269.3$ & $1,341.4$ & 1.2 \\
\hline Galway & 188.9 & 209.1 & 231.3 & 249.9 & 256.9 & 1.6 \\
\hline Kerry & 126.1 & 132.5 & 139.6 & 145.1 & 147.1 & 0.8 \\
\hline Kildare & 135.0 & 163.9 & 186.0 & 209.7 & 221.5 & 2.5 \\
\hline Kilkenny & 75.3 & 80.3 & 87.4 & 95.1 & 97.5 & 1.3 \\
\hline Laois & 52.9 & 58.8 & 66.9 & 80.3 & 84.3 & 2.4 \\
\hline Leitrim & 25.1 & 25.8 & 28.9 & 31.7 & 31.9 & 1.2 \\
\hline Limerick & 165.0 & 175.3 & 183.8 & 191.3 & 194.0 & 0.8 \\
\hline Longford & 30.2 & 31.1 & 34.3 & 38.9 & 40.7 & 1.5 \\
\hline Louth & 92.2 & 101.8 & 111.1 & 122.5 & 128.3 & 1.7 \\
\hline Mayo & 111.5 & 117.4 & 123.6 & 130.3 & 129.9 & 0.8 \\
\hline Meath & 109.7 & 134.0 & 162.6 & 183.6 & 194.2 & 2.9 \\
\hline Monaghan & 51.3 & 52.6 & 55.9 & 60.3 & 61.1 & 0.9 \\
\hline Offaly & 59.1 & 63.7 & 70.8 & 76.5 & 77.6 & 1.4 \\
\hline Roscommon & 52.0 & 53.8 & 58.7 & 63.9 & 64.3 & 1.1 \\
\hline Sligo & 55.8 & 58.2 & 60.8 & 65.2 & 65.2 & 0.8 \\
\hline Tipperary & 133.5 & 140.1 & 149.0 & 158.3 & 158.9 & 0.9 \\
\hline Waterford & 94.7 & 101.5 & 107.8 & 113.5 & 115.7 & 1.0 \\
\hline Westmeath & 63.3 & 71.9 & 79.2 & 85.9 & 88.4 & 1.7 \\
\hline Wexford & 104.4 & 116.6 & 131.5 & 144.9 & 149.1 & 1.8 \\
\hline Wicklow & 102.7 & 114.7 & 126.0 & 136.2 & 141.8 & 1.6 \\
\hline
\end{tabular}

Source: CSO, Census, various issues. 
TABLE B.2 POPULATION PROJECTIONS BY COUNTY, 2016-2040

\begin{tabular}{|c|c|c|c|c|c|c|c|c|}
\hline & \multicolumn{5}{|c|}{ Population ('000), baseline } & \multicolumn{3}{|c|}{ Annual Growth, 2016-2040 } \\
\hline & 2016 & 2021 & 2026 & 2031 & 2040 & $\begin{array}{c}\text { Baseline } \\
\%\end{array}$ & $\begin{array}{c}\text { High } \\
\text { Migration } \\
\%\end{array}$ & $\begin{array}{c}\text { Low } \\
\text { Migration } \\
\%\end{array}$ \\
\hline State & $4,739.6$ & $5,031.8$ & $5,238.6$ & $5,400.2$ & $5,665.5$ & 0.7 & 1.0 & 0.7 \\
\hline Carlow & 56.7 & 60.4 & 63.6 & 66.5 & 72.1 & 1.0 & 1.2 & 0.9 \\
\hline Cavan & 75.8 & 80.0 & 83.0 & 85.6 & 91.0 & 0.8 & 1.0 & 0.7 \\
\hline Clare & 118.3 & 123.4 & 126.7 & 129.5 & 134.9 & 0.5 & 0.8 & 0.5 \\
\hline Cork & 540.5 & 573.6 & 597.8 & 617.7 & 649.8 & 0.8 & 1.0 & 0.7 \\
\hline Donegal & 158.5 & 164.9 & 169.3 & 173.2 & 181.1 & 0.6 & 0.8 & 0.5 \\
\hline Dublin & $1,341.4$ & $1,446.3$ & $1,515.0$ & $1,558.7$ & $1,608.2$ & 0.8 & 1.1 & 0.7 \\
\hline Galway & 256.9 & 269.1 & 277.5 & 283.9 & 294.1 & 0.6 & 0.8 & 0.5 \\
\hline Kerry & 147.1 & 154.7 & 160.5 & 165.5 & 174.7 & 0.7 & 0.9 & 0.6 \\
\hline Kildare & 221.5 & 238.9 & 252.2 & 263.7 & 283.4 & 1.0 & 1.2 & 1.0 \\
\hline Kilkenny & 97.5 & 103.1 & 107.8 & 112.2 & 120.8 & 0.9 & 1.0 & 0.8 \\
\hline Laois & 84.3 & 90.8 & 95.8 & 100.1 & 108.3 & 1.0 & 1.2 & 1.0 \\
\hline Leitrim & 31.9 & 33.3 & 34.3 & 35.2 & 37.4 & 0.7 & 0.9 & 0.6 \\
\hline Limerick & 194.0 & 204.3 & 211.3 & 216.8 & 225.1 & 0.6 & 0.8 & 0.5 \\
\hline Longford & 40.7 & 43.4 & 45.5 & 47.3 & 50.6 & 0.9 & 1.1 & 0.8 \\
\hline Louth & 128.3 & 135.4 & 140.4 & 144.6 & 152.3 & 0.7 & 0.9 & 0.6 \\
\hline Mayo & 129.9 & 132.3 & 133.2 & 133.5 & 135.1 & 0.2 & 0.4 & 0.1 \\
\hline Meath & 194.2 & 208.8 & 220.2 & 230.5 & 250.0 & 1.1 & 1.3 & 1.0 \\
\hline Monaghan & 61.1 & 63.8 & 65.6 & 67.1 & 70.1 & 0.6 & 0.8 & 0.5 \\
\hline Offaly & 77.6 & 82.6 & 86.6 & 90.3 & 97.1 & 0.9 & 1.1 & 0.9 \\
\hline Roscommon & 64.3 & 67.0 & 69.2 & 71.3 & 75.8 & 0.7 & 0.9 & 0.6 \\
\hline Sligo & 65.2 & 68.4 & 70.9 & 73.2 & 77.4 & 0.7 & 0.9 & 0.6 \\
\hline Tipperary & 158.9 & 165.8 & 170.4 & 174.2 & 182.0 & 0.6 & 0.8 & 0.5 \\
\hline Waterford & 115.7 & 120.4 & 123.9 & 127.0 & 133.2 & 0.6 & 0.7 & 0.5 \\
\hline Westmeath & 88.4 & 94.2 & 98.3 & 101.7 & 107.5 & 0.8 & 1.0 & 0.7 \\
\hline Wexford & 149.1 & 156.4 & 162.2 & 167.4 & 178.0 & 0.7 & 0.9 & 0.7 \\
\hline Wicklow & 141.8 & 150.5 & 157.4 & 163.6 & 175.3 & 0.9 & 1.1 & 0.8 \\
\hline
\end{tabular}

Source: Authors' calculations. 
TABLE B.3 STRUCTURAL HOUSING DEMAND PROJECTIONS BY LOCAL AUTHORITY, 2017-2040

\begin{tabular}{|c|c|c|c|c|c|c|c|c|}
\hline & \multicolumn{5}{|c|}{ Baseline } & \multicolumn{3}{|c|}{2040} \\
\hline & 2017 & 2021 & 2026 & 2031 & 2040 & $\begin{array}{c}\text { High } \\
\text { migration }\end{array}$ & $\begin{array}{c}\text { Low } \\
\text { migration }\end{array}$ & $\begin{array}{c}50: 50 \\
\text { City }\end{array}$ \\
\hline State & 27,721 & 30,852 & 27,398 & 27,821 & 24,291 & 31,625 & 23,820 & 24,271 \\
\hline Carlow & 328 & 395 & 398 & 423 & 392 & 460 & 381 & 332 \\
\hline Cavan & 364 & 451 & 454 & 496 & 448 & 567 & 437 & 374 \\
\hline Clare & 482 & 591 & 567 & 583 & 458 & 633 & 446 & 290 \\
\hline Cork City & 833 & 962 & 900 & 998 & 696 & 871 & 684 & 970 \\
\hline Cork County & 2,320 & 2,583 & 2,259 & 2,206 & 2,040 & 2,634 & 1,999 & 2,879 \\
\hline Donegal & 668 & 875 & 892 & 979 & 827 & 1,082 & 806 & 734 \\
\hline Dublin - Dublin City & 4,190 & 4,333 & 3,278 & 3,415 & 3,293 & 4,344 & 3,277 & 3,086 \\
\hline Dublin - DL-Rathdown & 1,756 & 1,930 & 1,636 & 1,550 & 1,296 & 1,703 & 1,267 & 1,231 \\
\hline Dublin - Fingal & 2,034 & 2,152 & 1,381 & 977 & 743 & 1,309 & 758 & 642 \\
\hline Dublin - South Dublin & 1,952 & 2,058 & 1,491 & 1,233 & 1,087 & 1,591 & 1,082 & 1,000 \\
\hline Galway City & 296 & 297 & 284 & 341 & 185 & 293 & 183 & 478 \\
\hline Galway County & 1,030 & 1,144 & 1,021 & 953 & 843 & 1,100 & 815 & 1,587 \\
\hline Kerry & 779 & 929 & 879 & 926 & 833 & 1,048 & 813 & 430 \\
\hline Kildare & 1,397 & 1,494 & 1,464 & 1,517 & 1,281 & 1,601 & 1,249 & 1,155 \\
\hline Kilkenny & 529 & 574 & 600 & 663 & 675 & 781 & 659 & 547 \\
\hline Laois & 548 & 613 & 611 & 659 & 631 & 745 & 619 & 444 \\
\hline Leitrim & 113 & 161 & 171 & 192 & 173 & 225 & 168 & 113 \\
\hline Limerick & 1,231 & 1,263 & 1,110 & 1,101 & 892 & 1,186 & 870 & 1,826 \\
\hline Longford & 269 & 306 & 312 & 332 & 302 & 360 & 296 & 259 \\
\hline Louth & 743 & 841 & 812 & 853 & 744 & 932 & 725 & 743 \\
\hline Mayo & 296 & 429 & 412 & 449 & 325 & 501 & 312 & 310 \\
\hline Meath & 1,090 & 1,207 & 1,230 & 1,371 & 1,266 & 1,549 & 1,236 & 1,140 \\
\hline Monaghan & 264 & 320 & 309 & 344 & 324 & 418 & 316 & 268 \\
\hline Offaly & 462 & 506 & 518 & 561 & 519 & 622 & 508 & 356 \\
\hline Roscommon & 305 & 372 & 404 & 457 & 410 & 508 & 400 & 273 \\
\hline Sligo & 378 & 463 & 441 & 461 & 402 & 513 & 392 & 332 \\
\hline Tipperary & 667 & 812 & 792 & 837 & 694 & 929 & 677 & 348 \\
\hline Waterford & 510 & 573 & 571 & 615 & 500 & 626 & 484 & 652 \\
\hline Westmeath & 507 & 574 & 530 & 535 & 426 & 543 & 415 & 334 \\
\hline Wexford & 701 & 805 & 844 & 911 & 814 & 970 & 792 & 462 \\
\hline Wicklow & 682 & 839 & 827 & 881 & 773 & 980 & 750 & 677 \\
\hline
\end{tabular}

Source: Authors' calculations. 
Whitaker Square,

Sir John Rogerson's Quay, Dublin 2

Telephone +35318632000

Email adminCesri.ie

Web www.esri.ie

Twitter RESRIDublin

ISBN 978-0-7070-0539-3 